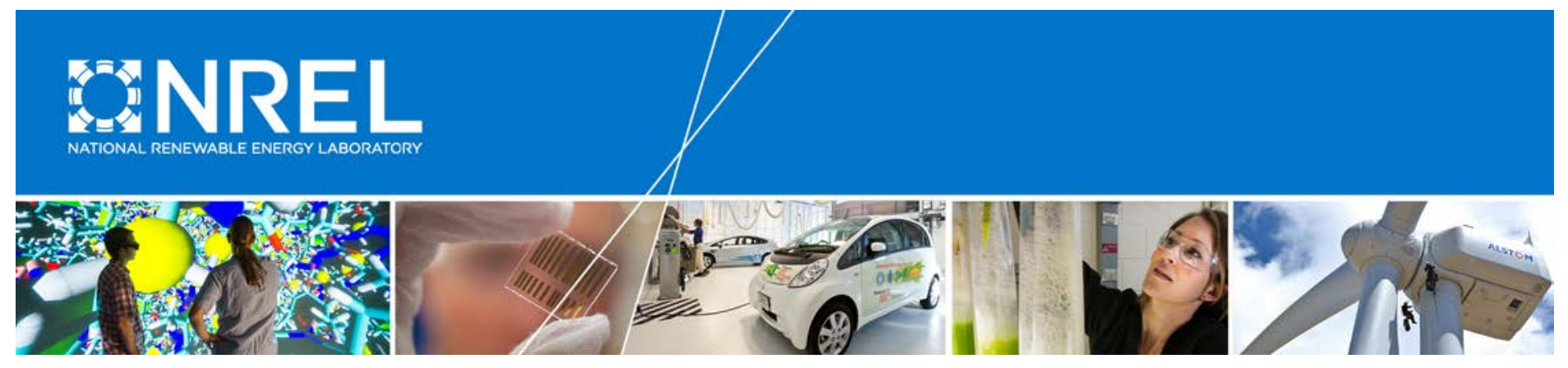

\title{
Consumer Views on Plug-in Electric Vehicles - National Benchmark Report (Second Edition)
}

Mark Singer

National Renewable Energy Laboratory

NREL is a national laboratory of the U.S. Department of Energy Office of Energy Efficiency \& Renewable Energy Operated by the Alliance for Sustainable Energy, LLC

This report is available at no cost from the National Renewable Energy Laboratory (NREL) at www.nrel.gov/publications.

Technical Report

NREL/TP-5400-67107

December 2016

Contract No. DE-AC36-08G028308 


\section{Consumer Views on Plug-in Electric Vehicles - National Benchmark Report (Second Edition)}

\section{Mark Singer}

National Renewable Energy Laboratory

Prepared under Task No. VTP2.2B00

NREL is a national laboratory of the U.S. Department of Energy Office of Energy Efficiency \& Renewable Energy Operated by the Alliance for Sustainable Energy, LLC

This report is available at no cost from the National Renewable Energy Laboratory (NREL) at www.nrel.gov/publications.

National Renewable Energy Laboratory 15013 Denver West Parkway Golden, CO 80401

303-275-3000 • www.nrel.gov

\section{Technical Report}

NREL/TP-5400-67107

December 2016

Contract No. DE-AC36-08G028308 


\section{NOTICE}

This report was prepared as an account of work sponsored by an agency of the United States government. Neither the United States government nor any agency thereof, nor any of their employees, makes any warranty, express or implied, or assumes any legal liability or responsibility for the accuracy, completeness, or usefulness of any information, apparatus, product, or process disclosed, or represents that its use would not infringe privately owned rights. Reference herein to any specific commercial product, process, or service by trade name, trademark, manufacturer, or otherwise does not necessarily constitute or imply its endorsement, recommendation, or favoring by the United States government or any agency thereof. The views and opinions of authors expressed herein do not necessarily state or reflect those of the United States government or any agency thereof.

This report is available at no cost from the National Renewable Energy Laboratory (NREL) at www.nrel.gov/publications.

Available electronically at SciTech Connect http:/www.osti.gov/scitech

Available for a processing fee to U.S. Department of Energy and its contractors, in paper, from:

U.S. Department of Energy

Office of Scientific and Technical Information

P.O. Box 62

Oak Ridge, TN 37831-0062

OSTI http://www.osti.gov

Phone: 865.576.8401

Fax: 865.576.5728

Email: reports@osti.gov

Available for sale to the public, in paper, from:

U.S. Department of Commerce

National Technical Information Service

5301 Shawnee Road

Alexandria, VA 22312

NTIS http://www.ntis.gov

Phone: 800.553 .6847 or 703.605 .6000

Fax: 703.605.6900

Email: orders@ntis.gov 


\section{Consumer Views Quick Facts}

\section{Vehicle Purchasing Behaviors}

- $58 \%$ of respondent households owned two or more vehicles.

- $56 \%$ of respondents stated their last vehicle purchases were sedans.

- $45 \%$ of respondents stated their next vehicle purchases would likely be sedans.

- $27 \%$ of respondent households had purchased vehicles in the last year.

\section{Plug-in Electric Vehicle Awareness}

- $46 \%$ of respondents were able to name a specific plug-in electric vehicle make and model.

- $43 \%$ of respondents reported having seen plug-in electric vehicles in parking lots.

- $46 \%$ of respondents stated plug-in hybrid electric vehicles were just as good as, or better than, traditional gasoline vehicles.

- $41 \%$ of respondents stated all-electric vehicles were just as good as, or better than traditional gasoline vehicles.

- $23 \%$ of respondents stated they would consider or expect to purchase plug-in hybrid electric vehicles for their next vehicle purchase or lease.

- $19 \%$ of respondents stated they would consider or expect to purchase all-electric vehicles for their next vehicle purchase or lease.

\section{Barriers to Plug-in Electric Vehicle Acceptance}

- An all-electric vehicle would need to be able to travel 300 miles on a single charge in order for $46 \%$ of respondents to be willing to consider purchasing one.

- $20 \%$ of respondents were aware of charging stations on the routes they regularly drove.

- $49 \%$ of respondents could consistently park their vehicles near electrical outlets at home.

- $49 \%$ of respondents would be willing to pay incremental costs for plug-in electric vehicles.

\section{Plug-in Electric Vehicle Acceptance}

- Respondents aware of plug-in electric vehicle charging stations were more likely than respondents overall to view plug-in electric vehicles positively and be willing to consider purchasing them.

- Respondents who were able to name one of the top best-selling plug-in electric vehicles were more likely than respondents overall to view plug-in electric vehicles positively and be willing to consider purchasing them.

- Respondents aged 35 or younger were more likely than respondents overall to view plug-in electric vehicles positively and be willing to consider purchasing them.

The above findings are based on a February 2016 study that is the second in a series of annual studies tracking consumer attitudes toward plug-in electric vehicles. The study covered a 1,008household sample designed to be representative of the United States population. 


\section{Acronyms}

ACS

AEV

EV

HEV

NREL

ORC

PEV

PHEV
American Community Survey

all-electric vehicle

electric vehicle

hybrid electric vehicle

National Renewable Energy Laboratory

Opinion Research Corporation

plug-in electric vehicle

plug-in hybrid electric vehicle 


\section{Acknowledgments}

This work has been supported by the U.S. Department of Energy's Vehicle Technologies Office. Additional support came from the National Renewable Energy Laboratory, which is a national laboratory of the U.S. Department of Energy's Office of Energy Efficiency and Renewable Energy operated by the Alliance for Sustainable Energy, LLC.

The author would like to thank advanced vehicle technology deployment subject matter experts Alicia Birky, Aaron Brooker, Belinda Chen, Stacy Davis, David Greene, Zhenhong Lin, Changzheng Liu, Dawn Manley, Michael Nicholas, Aymeric Rousseau, Dan Santini, Tom Stephens, Joann Zhou, Caley Johnson, George Mitchell, and Margo Melendez who provided helpful insights into how vehicle technologies might be accepted into the marketplace.

The author would like to specifically thank David Gohlke, Rachael Nealer, and Jake Ward at the U.S. Department of Energy's Vehicle Technologies Office, who ensured that the resources necessary for this research would be available.

All judgments in the final analytic methodologies and interpretations are the responsibility of the author. 


\section{Table of Contents}

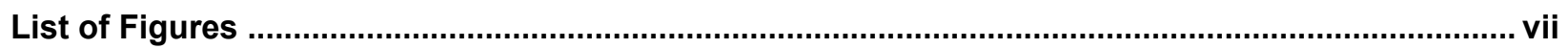

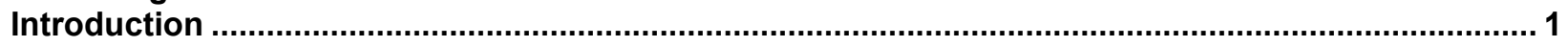

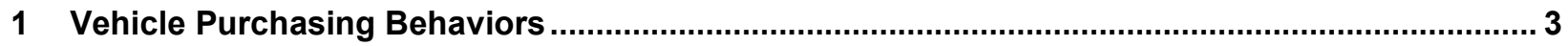

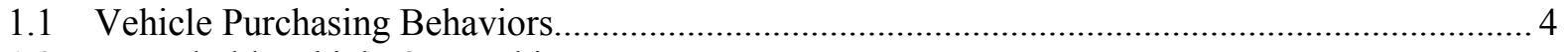





1.4 Time Since Last and Until Next Vehicle Purchase ….................................................................. 7

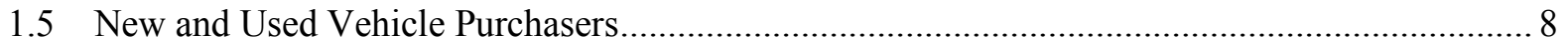



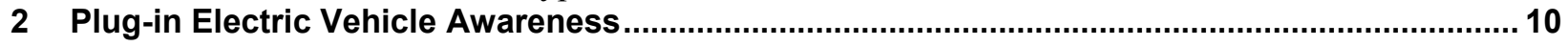

2.1 Plug-in Electric Vehicle Awareness and Acceptance Overview.............................................. 11

2.2 Ability to Name a Specific Plug-in Electric Vehicle Make and Model ...................................... 12

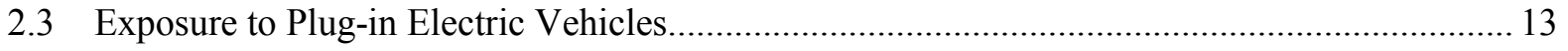

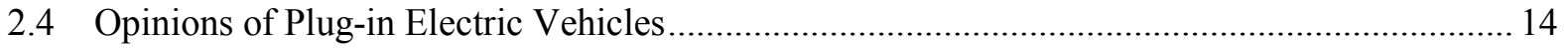

2.5 Consumers Considering Plug-in Electric Vehicles and Why .................................................. 15

2.6 Reasons for Considering Plug-in Electric Vehicles …............................................................ 16



3.1 Barriers to Plug-in Electric Vehicle Acceptance Overview ................................................... 18

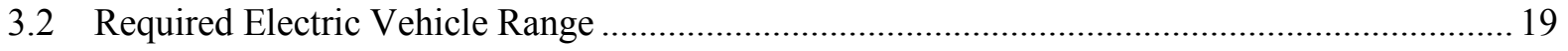

3.3 Perceived Ability to Charge a Plug-in Electric Vehicle .......................................................... 20

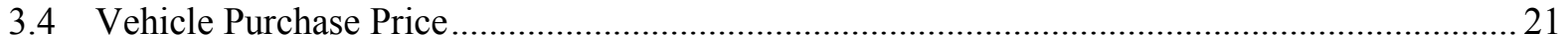

3.5 Willingness to Pay for a Plug-in Electric Vehicle................................................................ 22

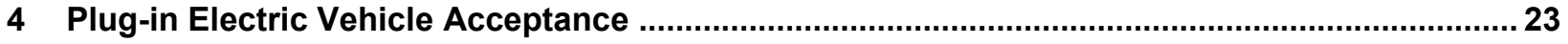

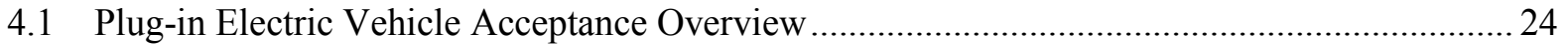

4.2 Perception of Plug-in Hybrid Electric vs. Conventional Vehicles ........................................... 27

4.3 Perception of All-Electric vs. Conventional Vehicles.............................................................. 28

4.4 Willingness to Consider Plug-in Hybrid Electric Vehicles by Segment .................................... 29

4.5 Willingness to Consider All-Electric Vehicles by Segment..................................................... 30

4.6 Demographics of Plug-in Electric Vehicle Perceptions ............................................................ 31

4.7 Demographics of Willingness to Consider Plug-in Electric Vehicles........................................ 32

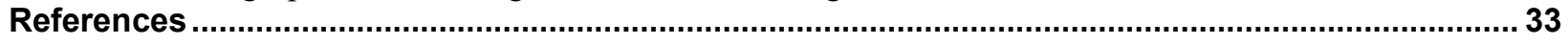




\section{List of Figures}

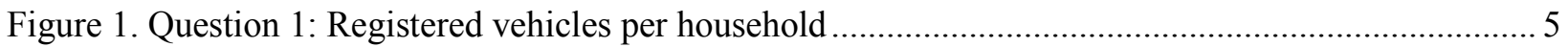

Figure 2. Comparison of registered vehicles per household over time ................................................... 5

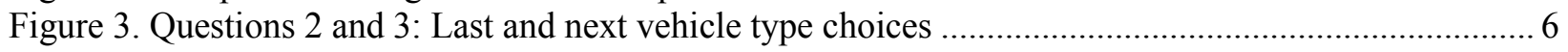

Figure 4. Question 4: Time since last vehicle purchase ......................................................................... 7

Figure 5. Question 5: Time until next vehicle purchase ....................................................................... 7

Figure 6. Time since last or until next vehicle purchase ...................................................................... 7

Figure 7. Question 5A: Likelihood of purchasing a new versus a used vehicle ................................... 8

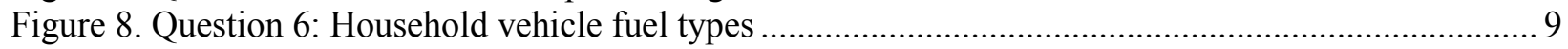

Figure 9. Question 7: Ability to name a PEV make and model ............................................................ 12

Figure 10. Question 8: Exposure to PEVs ....................................................................................... 13

Figure 11. Questions 9 and 11: Comparison of PHEVs and AEVs to gasoline vehicles......................... 14

Figure 12. Questions 9 and 11: Cumulative comparison of PHEVs and AEVs to gasoline vehicles ......... 14

Figure 13. Questions 10 and 12: Willingness to consider purchasing PHEVs and AEVs....................... 15

Figure 14. Questions 10 and 12: Cumulative willingness to consider purchasing PHEVs and AEVs ....... 15

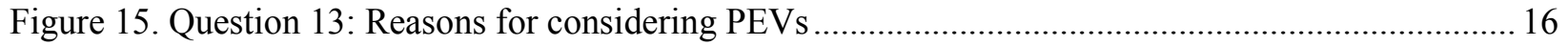

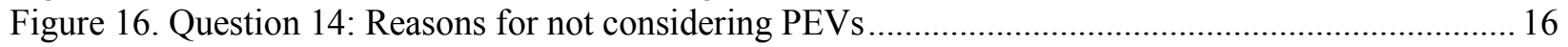

Figure 17. Question 15: PEV traits that could increase purchase consideration..................................... 16

Figure 18. Question 16: Required AEV range for purchase consideration.............................................. 19

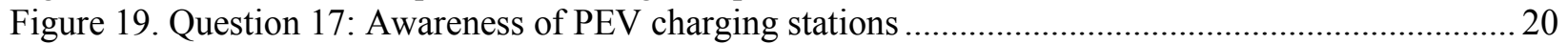

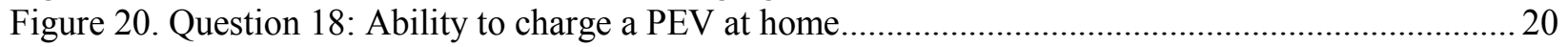

Figure 21. Question 19: Expected next vehicle purchase price ............................................................2

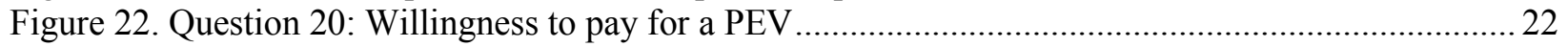

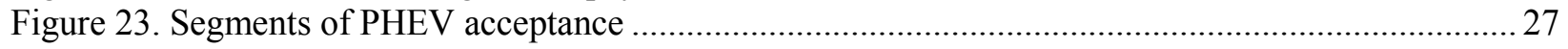

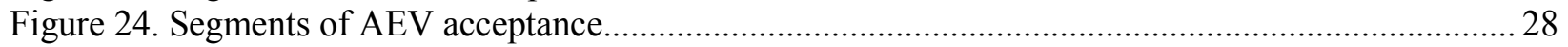

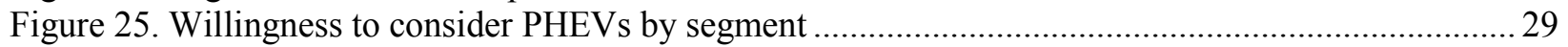

Figure 26. Willingness to consider AEVs by segment ................................................................... 30

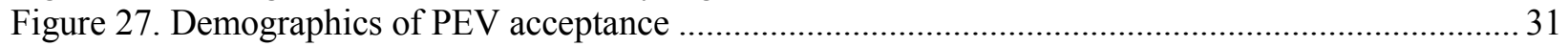

Figure 28. Demographics of willingness to consider PEVs.............................................................. 32 


\section{Introduction}

This report details broad American public sentiments toward issues that surround plug-in electric vehicles (PEVs) and is supported by the U.S. Department of Energy's Vehicle Technologies Office in alignment with its mission to develop and deploy these technologies to improve energy security, enhance mobility flexibility, reduce transportation costs, and increase environmental sustainability.

A PEV is broadly defined as a vehicle that can be plugged in, is powered by an electric motor, and uses energy stored in an onboard battery. The definition includes all-electric vehicles (AEVs) that are powered by electric motors only and plug-in hybrid electric vehicles (PHEVs) that can also be powered by an internal combustion engine fueled by petroleum fuel. The most recent generation of PEVs has been commercially available in the United States since December 2010. A PEV is different from a hybrid electric vehicle (HEV). An HEV is similar to a PHEV, as it is powered by an internal combustion engine and an electric motor that uses energy stored in a battery. However, the battery in an HEV cannot be plugged in; it is completely charged by fuel used in the internal combustion engine, either through a generator, or more indirectly through regenerative braking.

Understanding consumer sentiments can influence the prioritization of development efforts by identifying barriers to, and opportunities for, the broad acceptance of new technologies. The data detailed in this report represents the first two years of similar studies that are planned to be completed annually, allowing for tracking of public perception associated with PEV deployment efforts. This report is intended to support the evaluation of whether advancing vehicle technologies and changing vehicle availability align with evolving consumer expectations and interests over time.

This report primarily summarizes data captured in a February 2016 study that focused on respondents' sentiments about factors that influence PEV adoption.

- Section 1 captures respondent vehicle purchasing behavior independent of a particular vehicle technology.

- Section 2 details current consumer awareness and acceptance of PEV technologies.

- Section 3 captures metrics associated with known barriers to PEV acceptance, including battery capacity and vehicle costs.

- Section 4 highlights segments of the respondents in which PEV acceptance may be higher than the respondent group in total.

It is important to acknowledge that a person's stated preference in an interview about a hypothetical setting often does not match his or her revealed preference, which is demonstrated in an actual decision-making situation (Keane and Wasi 2013). This difference makes tracking actual consumer actions ultimately more valuable in understanding potential behavior. However, when technologies are not yet available or are new to a marketplace and actual behaviors cannot be tracked at scale, stated preferences provide some insights into how consumers may react in new circumstances. In this context, this report provides a supplemental source to validate other data and a new resource when no data are available. 
Most of the data presented in this report are the results of interviews conducted by the Opinion Research Corporation (ORC) for the National Renewable Energy Laboratory (NREL). The studies were conducted via telephone with randomly selected telephone numbers. The study in this report used a dual-frame sampling design in which the sample was drawn from independent landline and cell phone sample frames and is based on responses from individuals across the country who were at least 18 years old. Response samples were weight-adjusted to better ensure that the sample reflects the general U.S. population. The study relied on ORC's weighting mechanism, which pulls from data reported in the National Health Interview Survey and the U.S. Census Bureau's Current Population Survey. When ORC study data are presented, the specific ORC study number is noted along with the year of the study and the study sample size. The February 2016 study included 1,008 respondents and had a margin of error of $\pm 3 \%$ at the $95 \%$ confidence level. Smaller subgroups of the respondents will have larger error margins.

Most findings are compared to a similar study done one year prior to this one (Singer 2016), allowing the assessment of trends between years. In many instances throughout this report, the response percentages in tables and figures do not sum to exactly $100 \%$ because the raw data are rounded. For the same reason, summary data points called out in the body of the report may not match the results that were obtained by summing data from the tables and figures. 


\section{Vehicle Purchasing Behaviors}

\section{Contents}

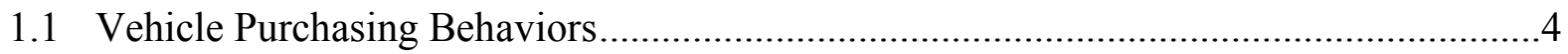

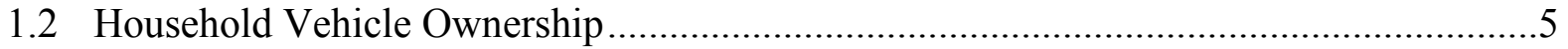

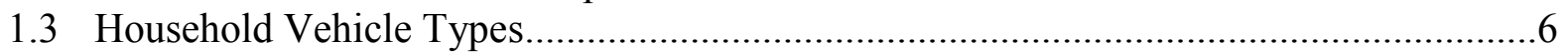

1.4 Time Since Last and Until Next Vehicle Purchase ............................................................

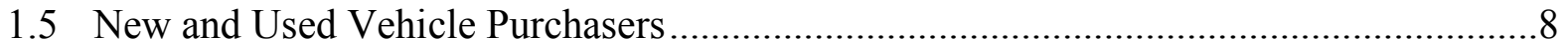

1.6 Household Vehicle Fuel Types …………………..................................................... 


\subsection{Vehicle Purchasing Behaviors}

The February 2016 study began by investigating aspects of the respondents' vehicle purchasing behaviors that are independent of a specific vehicle technology. Capturing these inherent metrics about the market highlights some particular barriers or benefit to PEV or other advanced vehicle technology adoption.

The first of these metrics covered is the number of household vehicles. If vehicle ownership decreases, the number of new purchases of any vehicle technology may also decline. Conversely, an increase in household vehicle ownership may provide additional opportunities for all vehicle technologies. Multivehicle households may be better suited for PEVs than single-vehicle households because AEVs specifically can be limited by battery capacity on longer trips. A household with multiple vehicles might be better able to provide alternative transportation for those trips than one without multiple vehicles. This study found little change in household vehicle ownership. The number of households owning two or more vehicles decreased from $60 \%$ in 2015 to $58 \%$ in 2016, but this change is within the 3\% margin of error for the study. In relation to a study completed in April 2007, the percentage of zero- and single-vehicle households increased slightly.

PEV acceptance depends, in part, on their availability in the vehicle types that consumers desire. Initial PEV offerings were focused in smaller sedans and have become available in a broader set of vehicle types. More than half $(56 \%)$ of respondents stated their last vehicle purchases were sedans; $45 \%$ stated their next vehicle purchases would likely be similar. Although these are large percentages of the vehicle market, PEVs need to be available in a broad set of vehicle types preferred by consumers if PEVs are to achieve very high percentages of vehicle purchases.

PEVs must also be available in the vicinity of the consumer. Currently, PEVs are not uniformly available across the country. While these regional differences are not investigated in this report, the lack of PEV availability in some areas can be a barrier to broad consumer acceptance.

Consumers' buying habits for vehicle purchases vary. An individual customer may purchase or lease a new vehicle every 3 years or even more frequently; others may keep their vehicles for 10 years or longer. This study found that $39 \%$ of respondents (consistent with 2015 results) either purchased vehicles in the last year or expected to purchase vehicles in the next year. Purchasers' interests in new or used vehicles also vary. A majority $(56 \%)$ of respondents stated they might consider a new vehicle for their next vehicle purchase; $43 \%$ stated they would be unlikely to consider a new vehicle and would likely purchase a used vehicle. These results were similar to 2015 results.

Finally, the study investigated the vehicle fuel types that respondents currently owned. As expected, the overwhelming majority of respondents $(82 \%)$ owned at least one traditional gasoline vehicle, but this number declined by $4 \%$ from $86 \%$ in 2015 . Nearly a fourth of respondents (23\%) stated they owned an alternative vehicle technology including diesel, ethanol, compressed natural gas, HEV, or PEV. Very small percentages (1\% each) of all respondents reported owning PHEVs or AEVs. Respondent ownership rates of traditional gasoline vehicles tracked closely with actual vehicle registration data. However, as shown in Figure 8, respondents consistently reported higher alternative vehicle technology ownership rates than those shown by actual vehicle registration data. 


\subsection{Household Vehicle Ownership}

Vehicle ownership appeared to be similar to prior study results. In February 2016, the mean number of vehicles owned by respondent households was 2.1 . A significant majority (75\%) reported owning two or fewer vehicles, while 58\% reported owning two or more vehicles. Results were consistent with those from February 2015. Compared to an April 2007 study, responses showed a slight decline in the number of two-vehicle households and a slight increase in zero- and single-vehicle households. Compared to the latest U.S. Census Bureau American Community Survey (ACS) data from 2013, February 2015 respondents had fewer one- and two-vehicle households and more households with four or more vehicles.

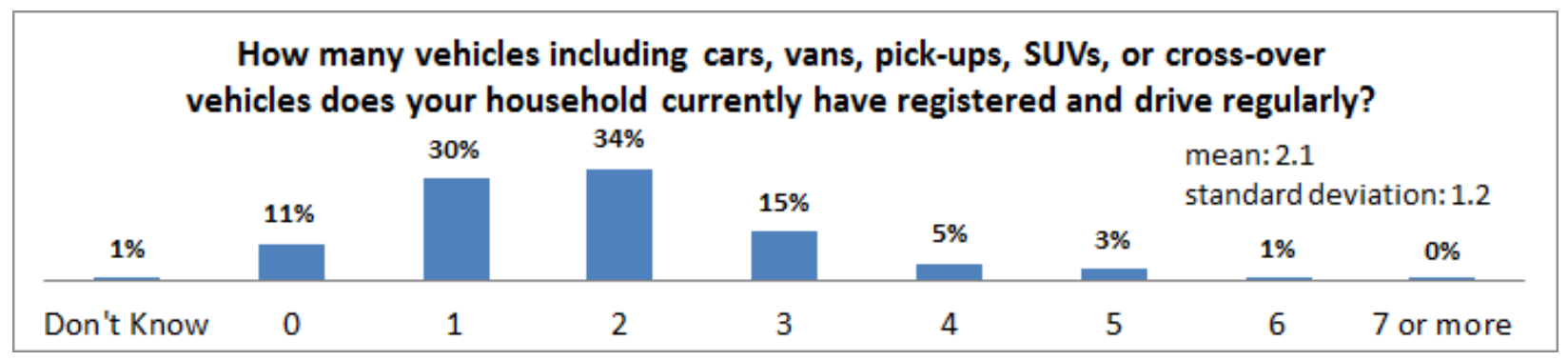

Figure 1. Question 1: Registered vehicles per household

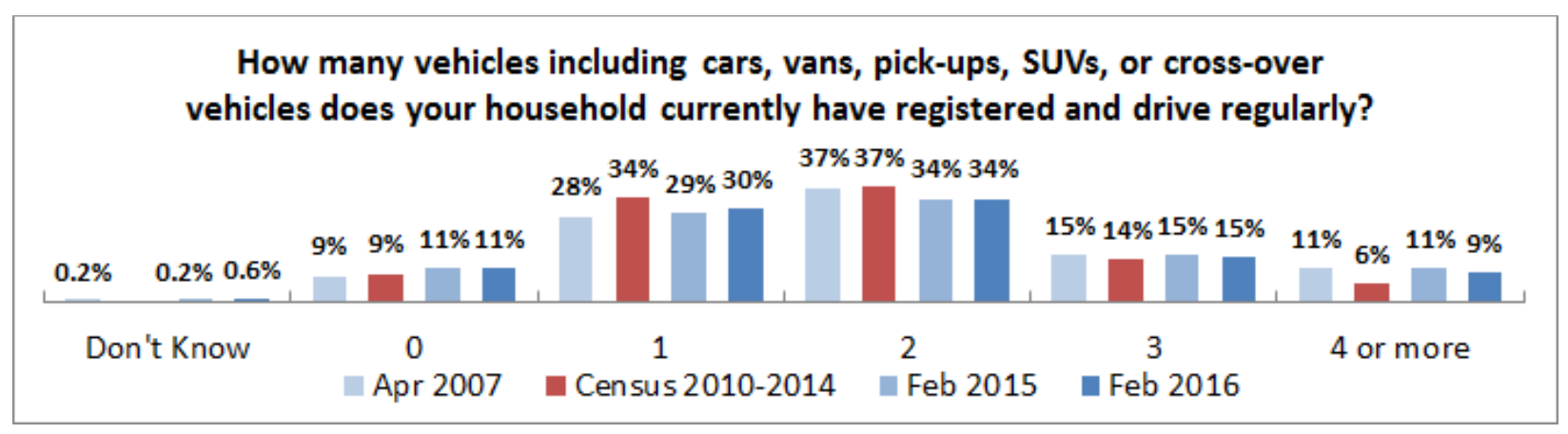

Figure 2. Comparison of registered vehicles per household over time

Sources: For 2016: ORC for NREL (2016), Study No. 725068, n=1,008. For 2015: ORC for NREL (2015), Study No. 724068, n=1,015. For 2007: ORC for NREL (2007), Study No. 716159, n=1,000.

U.S. Census Bureau. 2010-2014. "Household Size by Vehicles Available." American Community Survey 5-Year Estimates, USACS_14_5YR_B08201. Washington, D.C.: U.S. Census Bureau. Accessed August 3, 2016: http://factfinder.census.gov/faces/tableservices/jsf/pages/productview.xhtml?pid=ACS 14 5YR B08201\&prodType=t able.

Notes: Given that the current study covered 1,008 households and the ACS covered more than 3.5 million households, it is not concluded that the current study identifies a clear change in household vehicle ownership rates from those captured by the ACS. Rather, the comparison is shown to put the respondent group in context with the broader general public.

Section 4 of this report uses these results to classify single- and multivehicle households for investigation of how PEV acceptance may vary by respondent segments. 


\subsection{Household Vehicle Types}

The February 2016 study asked respondents to provide the vehicle types of their last vehicle purchases and the vehicle types they expected to purchase next. Respondents showed the strongest interest in sedans, which were categorized in the study as small and large cars. When their latest purchase choices were compared to what they expect to purchase next, the responses showed that interest may be shifting slightly away from sedans and toward pickup trucks and sport utility vehicles. This shift may represent the respondents' aspirations to shift to a new vehicle type rather than what their next vehicle purchase will ultimately be. Results are generally consistent with 2015 results.

For your last/next household vehicle purchase or lease, which one of the following did/will you purchase or lease?

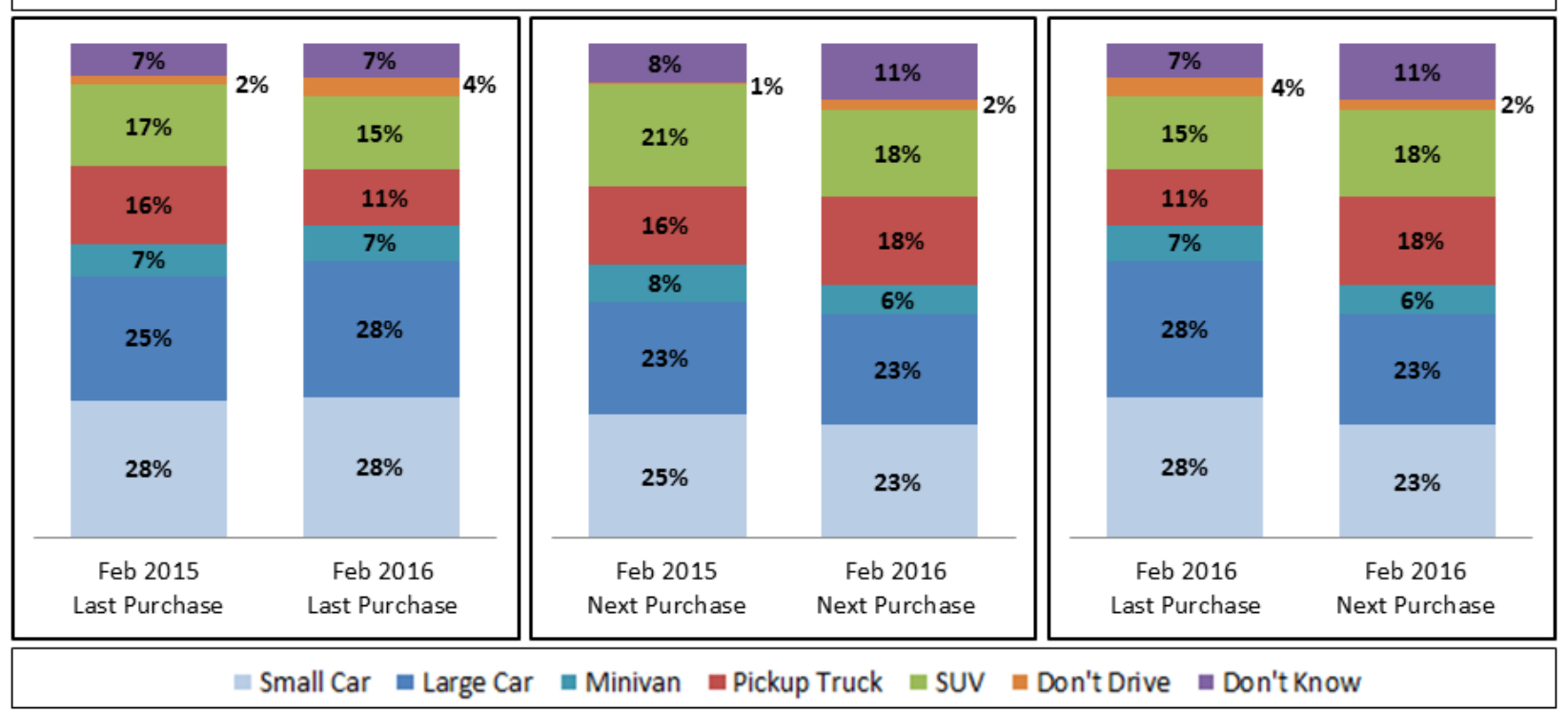

Figure 3. Questions 2 and 3: Last and next vehicle type choices

Sources: For 2016: ORC for NREL (2016), Study No. 725068, n=1,008. For 2015: ORC for NREL (2015), Study No. $724068, n=1,015$.

Note: Small cars were defined as being "smaller than the Chevy Malibu, Toyota Camry, or Ford Fusion" and large cars were defined as being the "same size or larger than the Chevy Malibu, Toyota Camry, or Ford Fusion." 


\subsection{Time Since Last and Until Next Vehicle Purchase}

Respondents in February 2016 were asked how long it had been since their last vehicle purchases and how long it would be before their next vehicle purchases. Consistent with 2015 , a majority $(60 \%)$ of respondents purchased vehicles in the last 3 years, and $46 \%$ expected to purchase vehicles within the next 3 years.

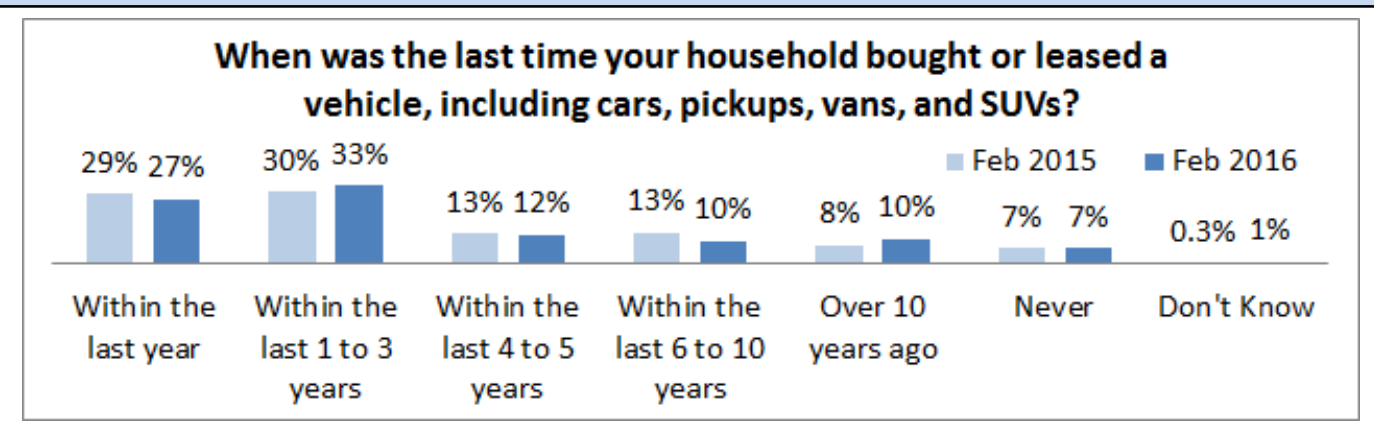

Figure 4. Question 4: Time since last vehicle purchase

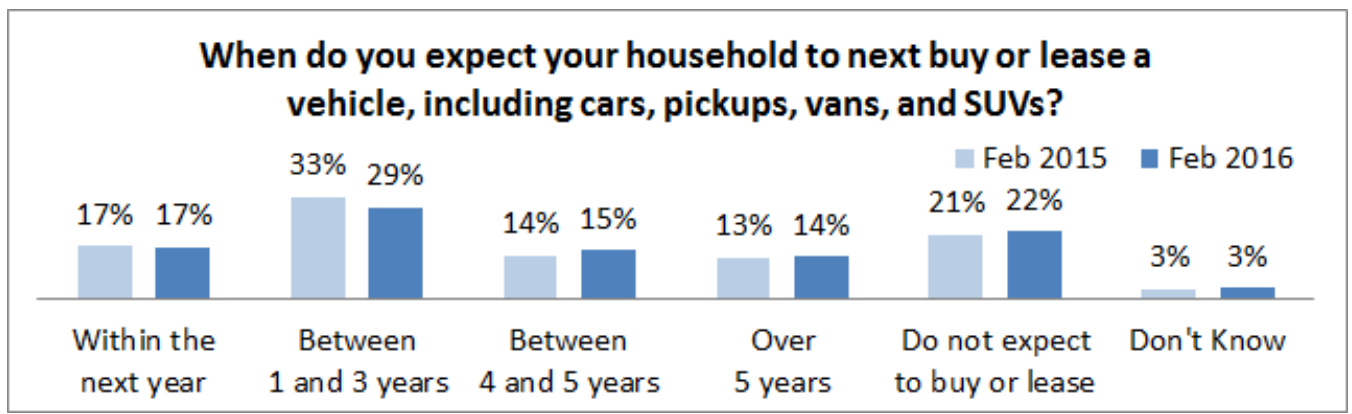

Figure 5. Question 5: Time until next vehicle purchase

Figure 6 displays a measure of how active respondents are in the market. Respondents who had either purchased a vehicle in the last year or intended to do so in the next year were classified to be within one year of a vehicle purchase. Of the remaining respondents, those that had purchased a vehicle in the last 1-3 years or intended to do so in the next 1-3 years were classified as being within 1-3 years of a vehicle purchase. The remaining segments followed similarly. Ultimately $39 \%$ of respondents were within 1 year of vehicle purchases.

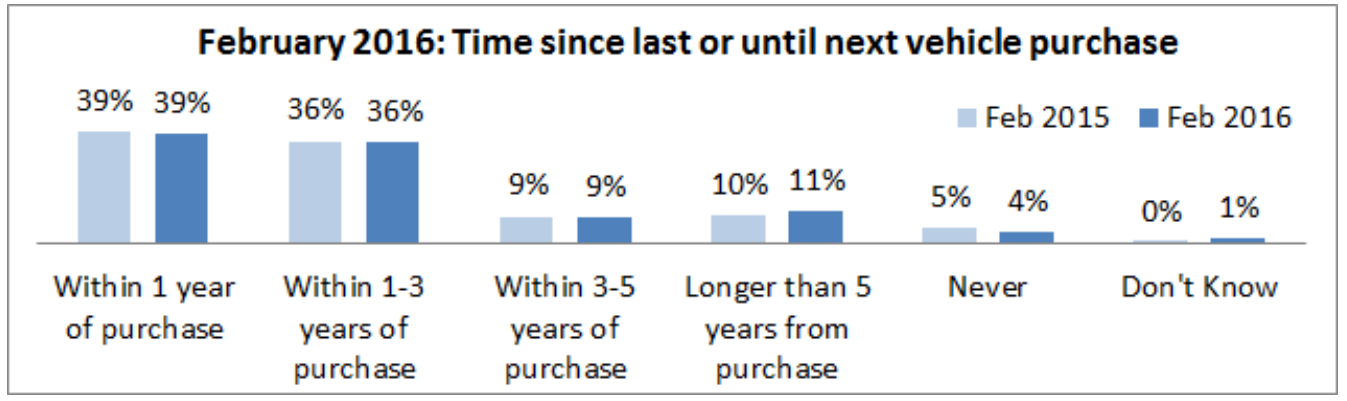

Figure 6. Time since last or until next vehicle purchase

Sources: For 2016: ORC for NREL (2016), Study No. 725068, n=1,008. For 2015: ORC for NREL (2015), Study No. $724068, n=1,015$. 


\subsection{New and Used Vehicle Purchasers}

Respondents in February 2016 were asked how likely they would be to purchase brand new vehicles versus used vehicles. Those that stated they "probably" or "definitely" will buy new vehicles made up $40 \%$ of respondents, and a similar percentage (43\%) stated that they were "not very likely" or "not at all likely" to buy new vehicles. The remaining $16 \%$ stated they would maybe purchase new vehicles. Results were similar to the 2015 study data. Those respondents who stated they would maybe purchase a new vehicle (down $4 \%$ from 2015) changed beyond the $3 \%$ margin of error.

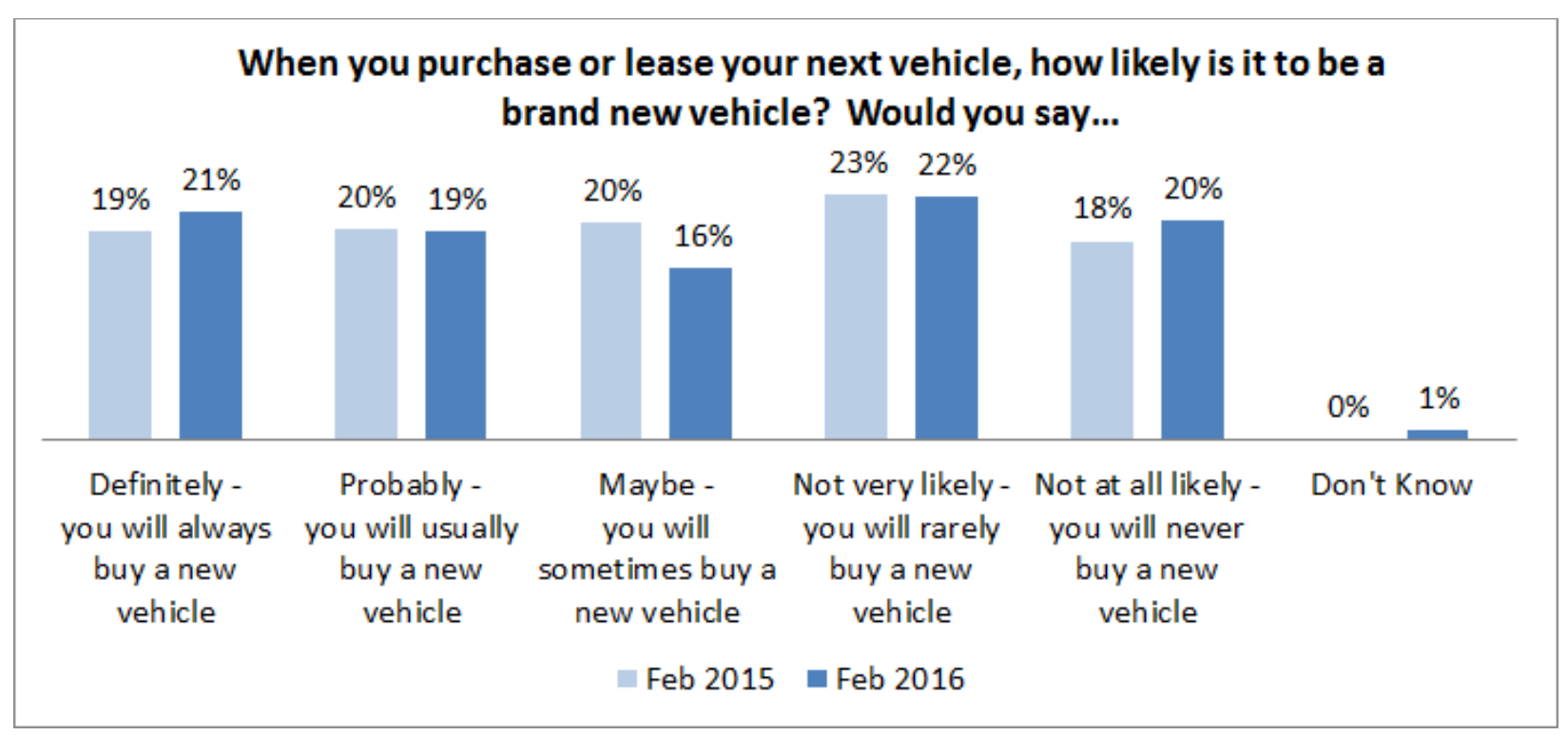

Figure 7. Question 5A: Likelihood of purchasing a new versus a used vehicle

Sources: For 2016: ORC for NREL (2016), Study No. 725068, n=789. For 2015: ORC for NREL (2015), Study No. $724068, \mathrm{n}=806$.

Notes: Those respondents who answered "do not expect to buy or lease another vehicle" when asked about the time until their next vehicle purchase in question 5 were not asked about the likelihood they would purchase a new or used vehicle in question $5 \mathrm{~A}$.

In Section 4 of this report, the $56 \%$ of respondents who stated they would "definitely," "probably," or "maybe" purchase new vehicles were classified as "new vehicle purchasers" because they all seemed to be stating they would consider new vehicles. The $43 \%$ of respondents who stated they were "not very likely" or "not at all likely" to purchase a new vehicle were classified as "used vehicle purchasers". This classification is not intended as a measure of an expected split between new and used car sales; rather, it is interpreted as an indication of whether or not a respondent would even consider a new vehicle. To put this split in context, in 2014 more than 42 million used vehicles were purchased while 16.5 million new vehicles were sold (NIADA 2015) -28\% of vehicle purchases in 2014 were for new vehicles. 


\subsection{Household Vehicle Fuel Types}

The overwhelming majority of households ( $82 \%)$ owned traditional gasoline vehicles in February 2016. Ethanol-capable and diesel vehicles were owned by $10 \%$ and $7 \%$ of respondents, respectively. Compressed natural gas and PEV technologies were owned by small percentages of respondents. Nearly a quarter $(23 \%)$ reported owning vehicles other than traditional gasoline vehicles. A small percentage (4\%) owned only vehicles of fuel type(s) other than traditional gasoline. Respondent ownership rates of technologies other than traditional gasoline were all higher than percentages of overall vehicle registrations. This is expected as respondent households can and do own multiple vehicles. Results are generally consistent with 2015 results, but a small decline was reported in the percentage of respondents who owned traditional gasoline vehicles and a similarly small increase was reported in the percentage of respondents who stated they did not own any of the technologies.

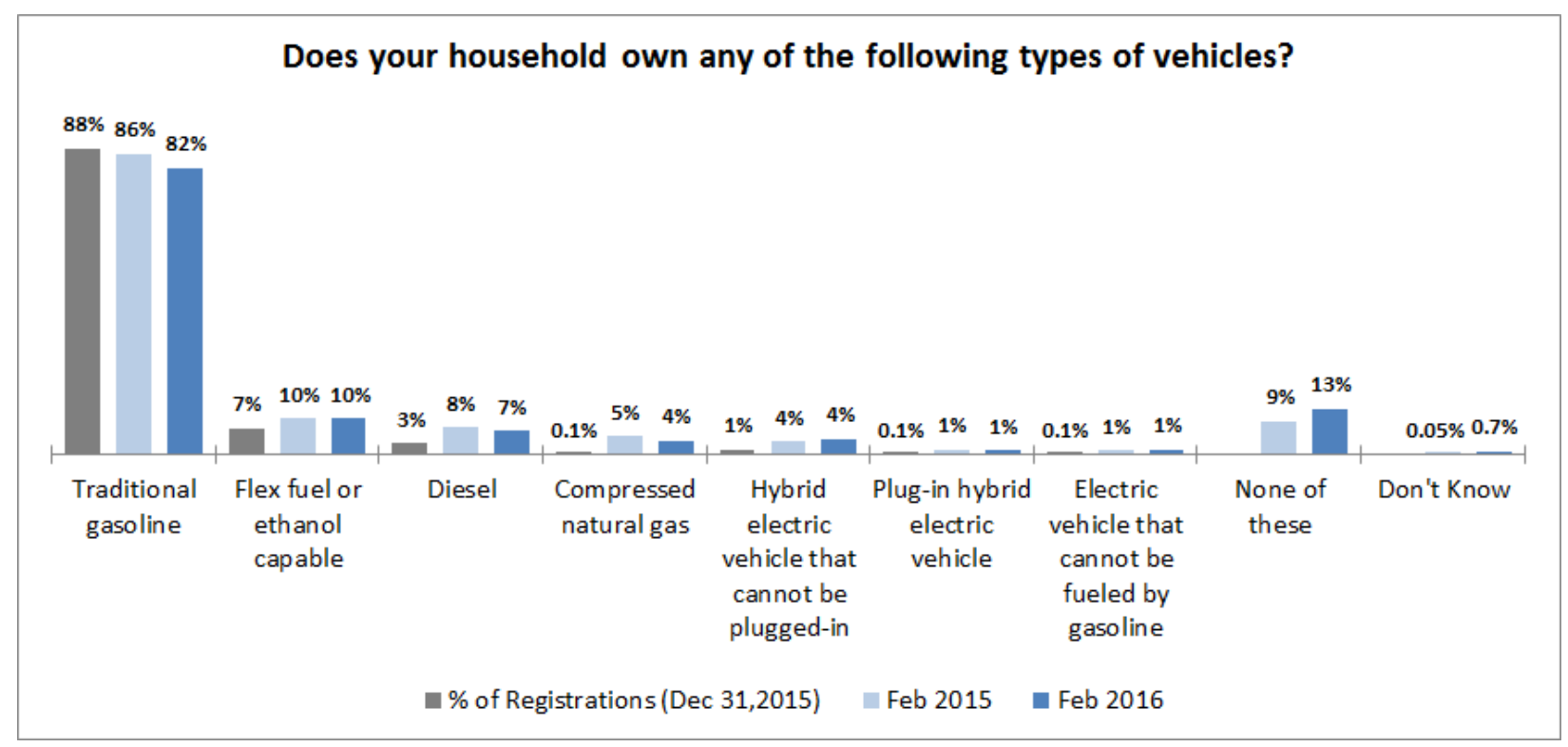

Figure 8. Question 6: Household vehicle fuel types

Sources: For 2016: ORC for NREL (2016), Study No. 725068, n=1,008. For 2015: ORC for NREL (2015), Study No. $724068, n=1,015$.

Polk, R.L. 2016. "POLK_VIO_DETAIL_2015." Golden, CO: National Renewable Energy Laboratory. Accessed April 20, 2016. 


\section{Plug-in Electric Vehicle Awareness}

\section{Contents}

2.1 Plug-in Electric Vehicle Awareness and Acceptance Overview.......................................11

2.2 Ability to Name a Specific Plug-in Electric Vehicle Make and Model ..........................12

2.3 Exposure to Plug-in Electric Vehicles.........................................................................

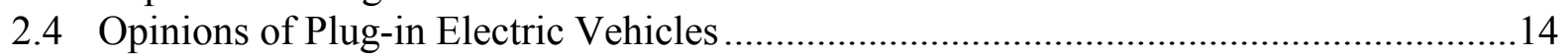

2.5 Consumers Considering Plug-in Electric Vehicles and Why ……..................................15

2.6 Reasons for Considering Plug-in Electric Vehicles .......................................................16 


\subsection{Plug-in Electric Vehicle Awareness and Acceptance Overview}

Consumers will purchase PEVs in large numbers only after they are aware of the technologies and are willing to consider purchasing PEVs. This study attempted to quantify respondent PEV awareness, acceptance, and interest.

The study asked respondents if they were able to name a specific PEV make and model. Nearly half (46\%) were able to name a specific PEV make and model and $41 \%$ were able to name one of the top 10 best-selling makes and models at the time of the study. Conversely, 54\% were not able to name a specific PEV make and model. In comparison with the 2015 results, there was a drop in the percentage of respondents able to name a specific PEV make and model, but the decrease was within the $3 \%$ margin of error of the study.

Respondents were also asked about their levels of exposure to PEVs. The theory of diffusion of innovations (Rogers 2010) describes how new technologies become accepted. Accordingly, a measure of exposure can serve as a prerequisite and proxy measure for future vehicle purchases. Some respondents reported direct exposure to PEVs through having sat in or driven one $(13 \%$ and 7\%, respectively). Respondents in 2015 reported a higher percentage (49\%) having seen PEVs in parking lots than respondents in 2016 (43\%).

PEV acceptance is measured in this study by how respondents view the technology compared to the current standard technology (i.e., traditional gasoline vehicles). This study found that PHEVs are viewed by $46 \%$ of respondents as being as good as or better than gasoline vehicles. This measure is down from $53 \%$ in 2015 and the change is greater than the 3\% margin of error of the study. A smaller percentage (41\%) said the same about AEVs (down from $45 \%$ in 2015). The largest changes were decreases in the percentages of respondents stating the technologies were better than traditional gasoline vehicles and increases in the percentages of respondents not having an opinion. As a matter of context, gasoline prices per gallon dropped from $\$ 2.30$ in February 2015 to $\$ 1.87$ in February 2016 (EIA 2016). The sentiments of respondents toward alternatives to traditional gasoline vehicles may have been affected in part by this decline.

Finally, respondents reported their willingness to consider purchasing PEVs. Nearly a quarter of respondents $(23 \%)$ stated they expected to purchase or expected to consider purchasing PHEVs. Similarly, $19 \%$ stated the same about AEVs. These percentages were similar to 2015 results, but the largest change in willingness to consider PEVs was an increase of those stating definitively that they will not purchase PEVs. The top reasons given for considering PEV purchases were that PEVs were viewed as being better for the environment and they would save money on fuel. The top reason for not considering the technology was that PEVs were viewed as being too expensive. 


\subsection{Ability to Name a Specific Plug-in Electric Vehicle Make and Model}

Respondents were asked if they could name a PEV, and $46 \%$ were able to name a specific vehicle make and model. Further, $41 \%$ were able to name at least one of the 10 top bestselling makes and models at the time of the study. These results are consistent with results from 2015. Only the Tesla Model S showed a measurable increase in respondent awareness.

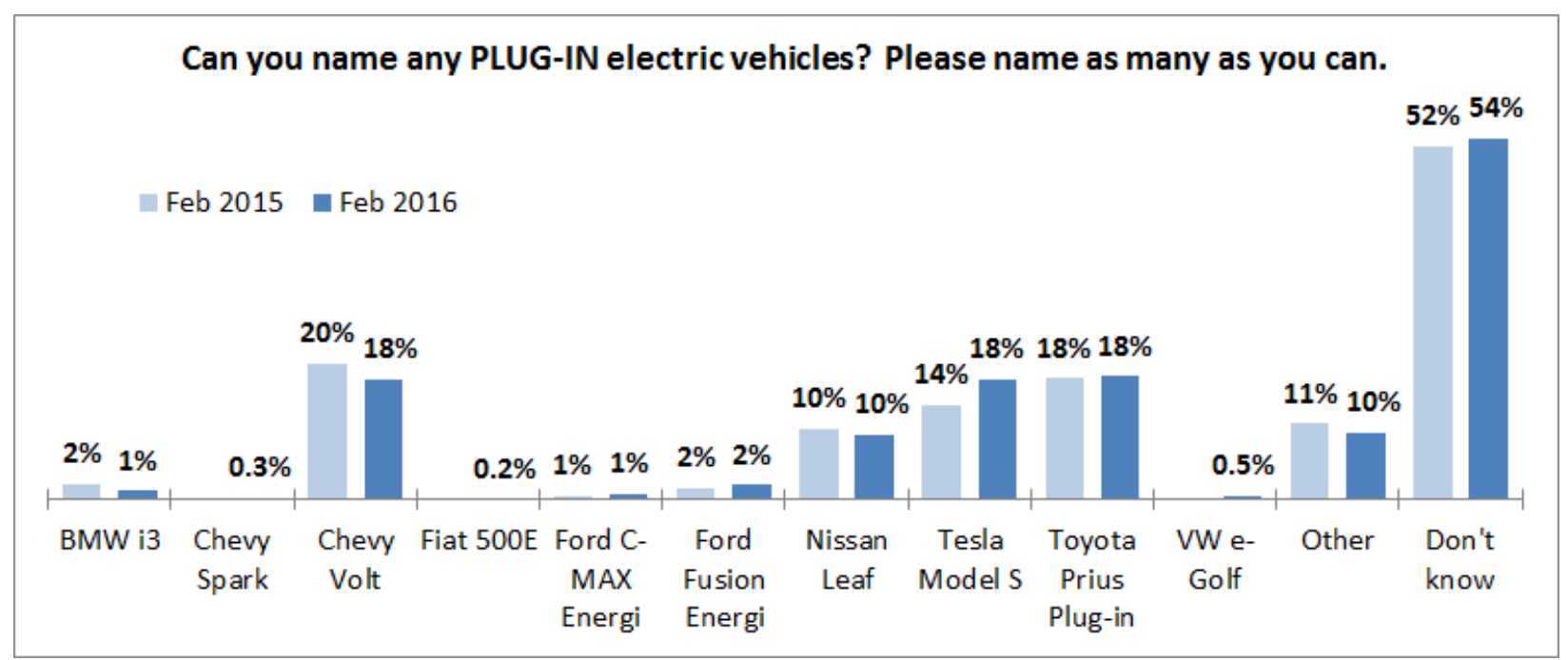

Figure 9. Question 7: Ability to name a PEV make and model

Sources: For 2016: ORC for NREL (2016), Study No. 725068, n=1,008. For 2015: ORC for NREL (2015), Study No. $724068, n=1,015$.

Note: The Toyota Prius was available at the time of the study as both an HEV and a PHEV; some respondents may have confused the two versions. A follow-up question asked respondents who mentioned only the Toyota Prius Plug-in in the initial question to name another make and model. Just $6.7 \%$ of respondents overall could name only the Toyota Prius Plug-in. If all these respondents were actually unaware of the Toyota Prius Plug-in PHEV, the percentage who were unable to name a PEV make and model would climb to $60 \%$ and the percentage who were aware of the Toyota Prius Plug-in would fall from $18 \%$ to $12 \%$ (rounding). 


\subsection{Exposure to Plug-in Electric Vehicles}

Respondents were asked how they had been exposed to PEVs. Nearly half (49\%) reported having firsthand exposure to PEVs by having been in one, having a neighbor with one, or having seen one in parking lots. A large majority (75\%) reported exposure to PEVs from advertisements or social media. A third of respondents (33\%) have heard of PEV tax incentives. Overall, $84 \%$ of respondents reported having been exposed to PEVs by one of the categories described in Figure 10. Respondents in 2015 were not asked about PEV ads, PEVs in social media, or PEV tax incentives.

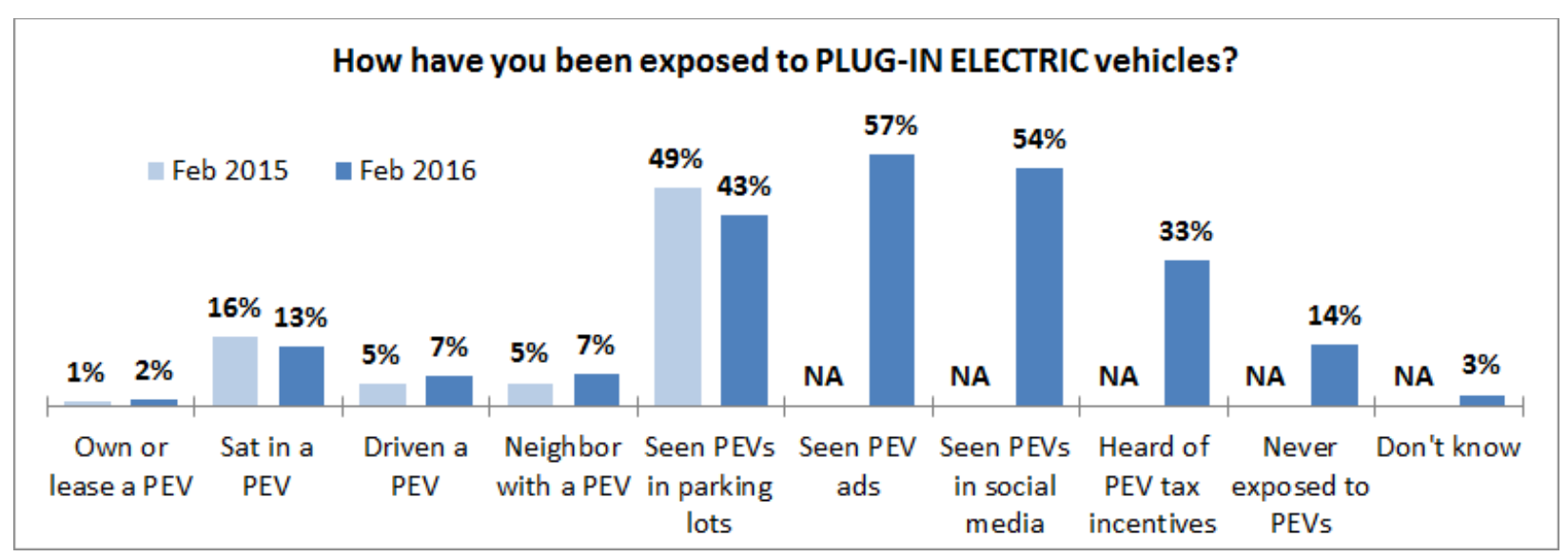

Figure 10. Question 8: Exposure to PEVs

Sources: For 2016: ORC for NREL (2016), Study No. 725068, n=1,008. For 2015: ORC for NREL (2015), Study No. $724068, n=1,015$.

Note: Respondents were given the following information before being asked about their exposure to and opinion of PEVs beginning with question 8: "Plug-in electric vehicles can be charged by being plugged into a household-type outlet or specially designed charging equipment. These can be defined as plug-in hybrids or pure electric vehicles. Not included in this definition are hybrids, such as the original Toyota Prius, that cannot be plugged in. The Chevy Volt is an example of a plug-in hybrid electric vehicle that can be powered by either the battery or the gasoline engine. The Tesla Model S or the Nissan Leaf are examples of pure electric vehicles powered only by their batteries." 


\subsection{Opinions of Plug-in Electric Vehicles}

When asked about their opinions of PEVs, respondents showed a preference for PHEVs over AEVs compared to traditional gasoline vehicles. Nearly half (46\%) stated PHEVs were "just as good as" or "better than" traditional gasoline vehicles; $41 \%$ stated AEVs were "just as good as" or "better than" traditional gasoline vehicles. Lower percentages of respondents in 2016 felt the technologies were "better than" traditional gasoline vehicles, but that decline did not result in an increase in the percentage of respondents stating the vehicles were "not as good as" traditional gasoline vehicles. Instead there was an increase in the percentage of respondents stating they did not know how the technologies compared.

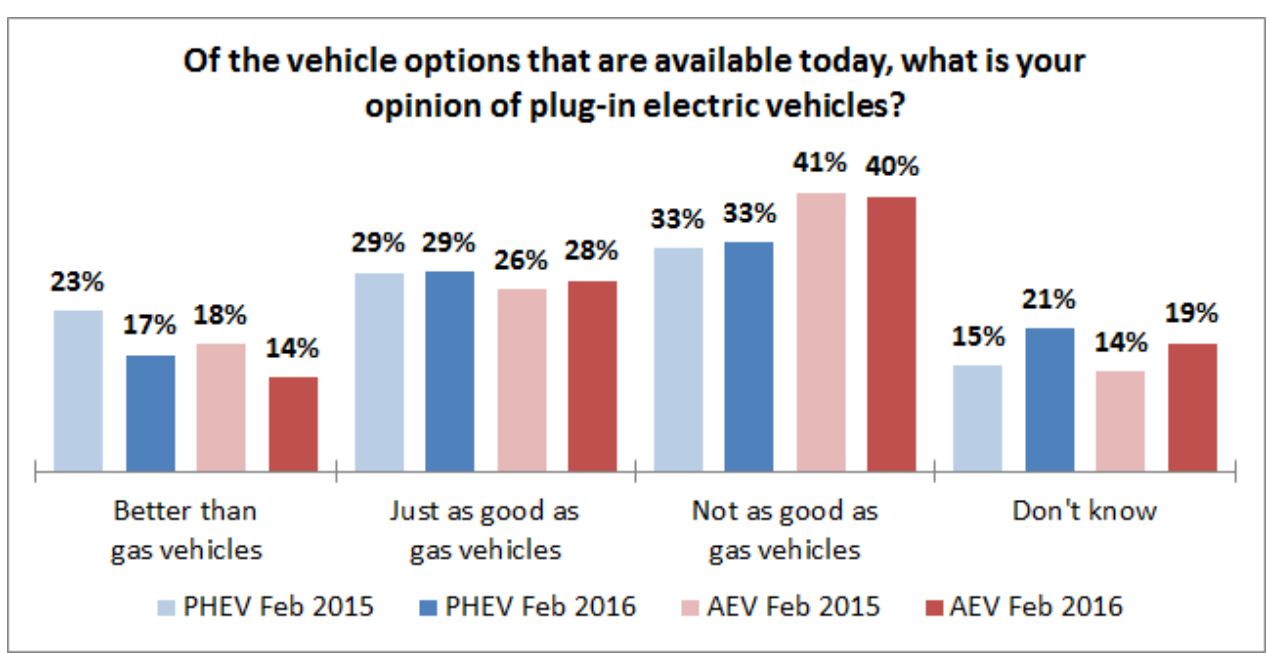

Figure 11. Questions 9 and 11: Comparison of PHEVs and AEVs to gasoline vehicles

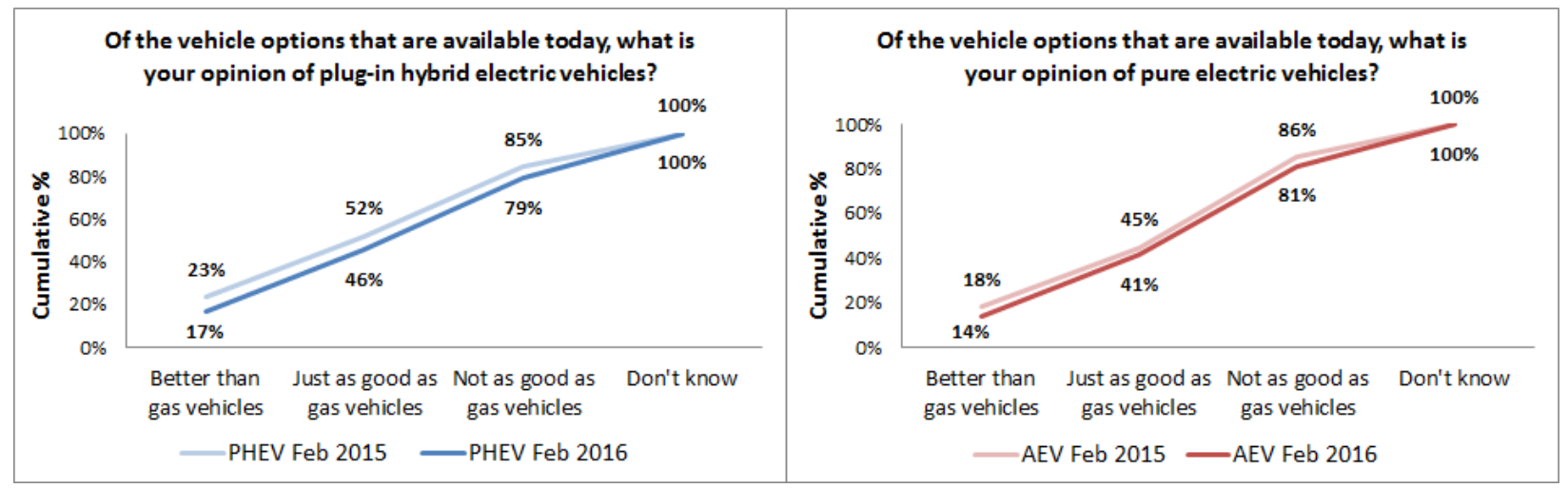

Figure 12. Questions 9 and 11: Cumulative comparison of PHEVs and AEVs to gasoline vehicles

Sources: For 2016: ORC for NREL (2016), Study No. 725068, n=1,008. For 2015 PHEVs: ORC for NREL (2015), Study No. 724068, n=506. For 2015 AEVs: ORC for NREL (2015), Study No. 724068, n=509.

Note: Respondents were given the following information before being asked about their exposure to and opinion of PEVs beginning with question 8: "Plug-in electric vehicles can be charged by being plugged into a household-type outlet or specially designed charging equipment. These can be defined as plug-in hybrids or pure electric vehicles. Not included in this definition are hybrids, such as the original Toyota Prius, that cannot be plugged in. The Chevy Volt is an example of a plug-in hybrid electric vehicle that can be powered by either the battery or the gasoline engine. The Tesla Model S or the Nissan Leaf are examples of pure electric vehicles powered only by their batteries." In the 2015 study, the respondent group was split. Roughly half of the respondents were asked about PHEV sentiments. The second half of respondents was asked about AEV sentiments. 


\subsection{Consumers Considering Plug-in Electric Vehicles and Why}

Respondents showed a greater interest in PHEVs compared to AEVs when asked if they would consider purchasing the vehicles. Nearly a quarter of respondents $(23 \%)$ stated they would consider or expect to purchase PHEVs; $19 \%$ stated they would consider or expect to purchase AEVs. A majority, $57 \%$ and $62 \%$, stated they would not purchase or lease PHEVs or AEVs, respectively. There was an increase in the percentage of respondents who said they will not purchase or lease PEVs from 2015. While within the margin of error, there was also a slight increase in the percentage stating they expected to purchase or lease PEVs.

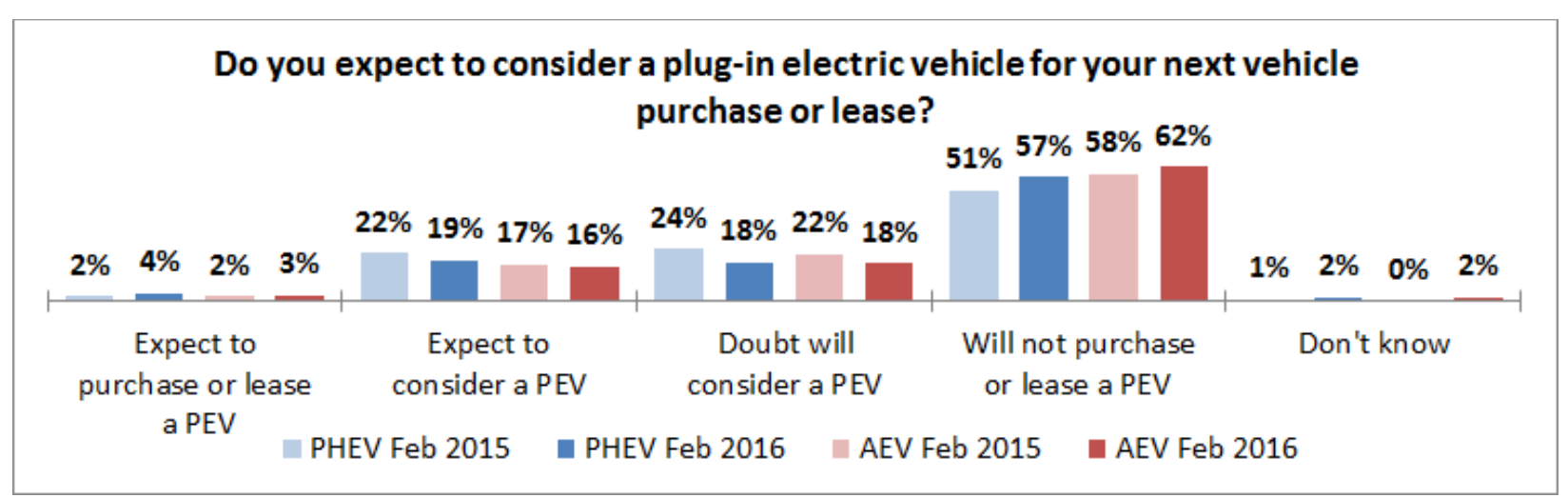

Figure 13. Questions 10 and 12: Willingness to consider purchasing PHEVs and AEVs

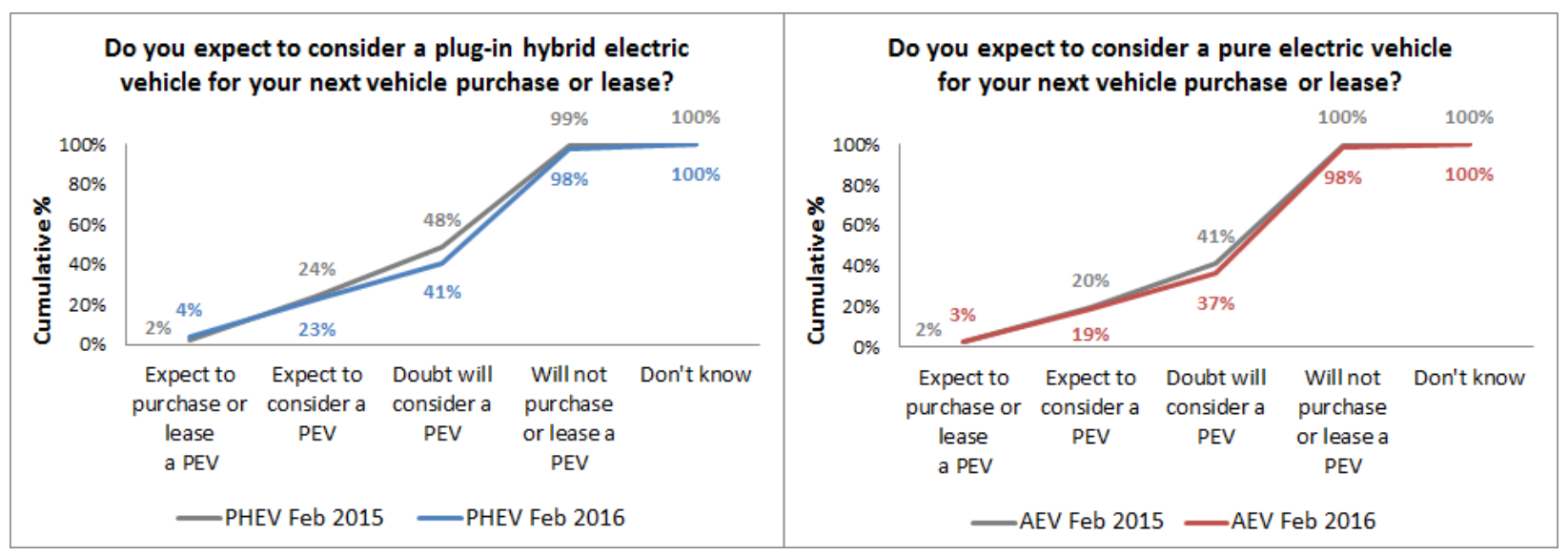

Figure 14. Questions 10 and 12: Cumulative willingness to consider purchasing PHEVs and AEVs

Sources: For 2016: ORC for NREL (2016), Study No. 725068, n=1,008. For 2015 PHEVs: ORC for NREL (2015), Study No. 724068, n=506. For 2015 AEVs: ORC for NREL (2015), Study No. 724068, n=509.

Note: Respondents were given the following information before being asked about their exposure to and opinion of PEVs beginning with question 8: "Plug-in electric vehicles can be charged by being plugged into a household-type outlet or specially designed charging equipment. These can be defined as plug-in hybrids or pure electric vehicles. Not included in this definition are hybrids, such as the original Toyota Prius, that cannot be plugged in. The Chevy Volt is an example of a plug-in hybrid electric vehicle that can be powered by either the battery or the gasoline engine. The Tesla Model S or the Nissan Leaf are examples of pure electric vehicles powered only by their batteries." In the 2015 study, the respondent group was split. Roughly half of the respondents were asked about PHEV sentiments. The second half of respondents was asked about AEV sentiments. 


\subsection{Reasons for Considering Plug-in Electric Vehicles}

The top reasons for considering PEVs were that PEVs were viewed as better for the environment and would provide fuel cost savings. Fewer respondents agreed with each reason for considering a PEV than in 2015. The primary reason for not considering PEVs (given by $55 \%$ ) was that the vehicles are too expensive. None of the other reasons given for not considering PEVs were given by a majority of respondents. Those not considering PEVs were asked about factors that might influence them to consider PEVs. A majority (59\% and 55\%, respectively) stated that if PEVs were truly better for the environment, or if they saved money on fuel, they would be more likely to consider PEVs.

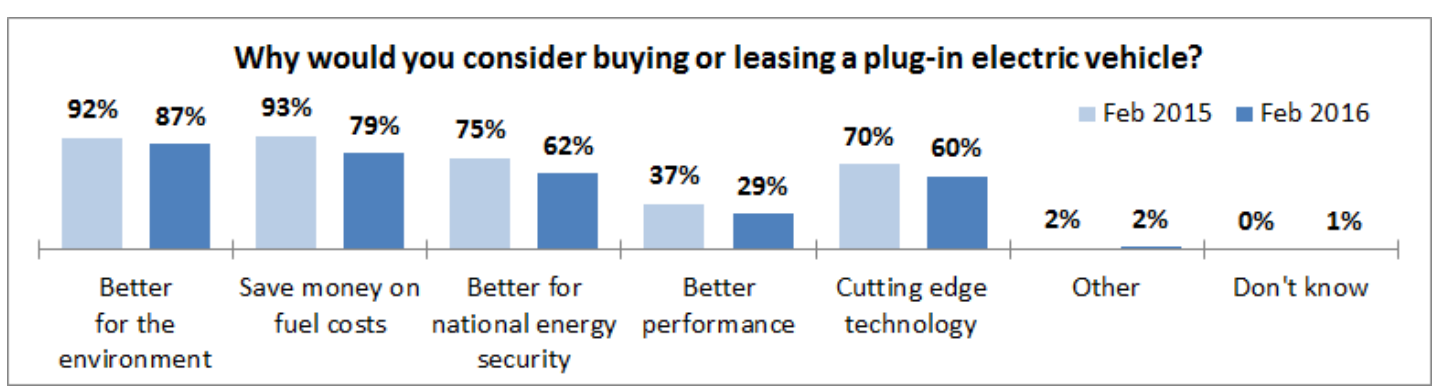

Figure 15. Question 13: Reasons for considering PEVs

Sources: For 2016: ORC for NREL (2016), Study No. 725068, n=256. For 2015: ORC for NREL (2015), Study No. 724068, $n=223$.

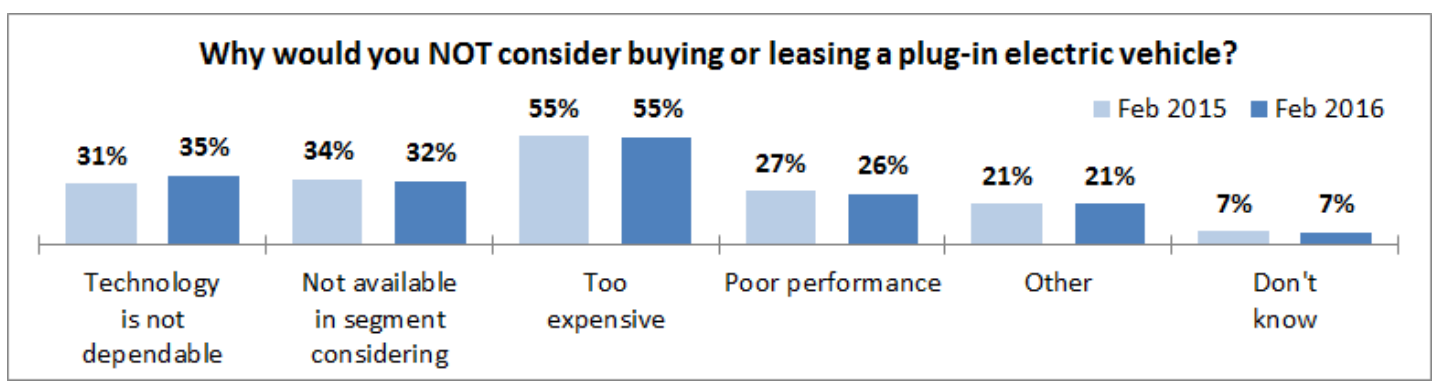

Figure 16. Question 14: Reasons for not considering PEVs

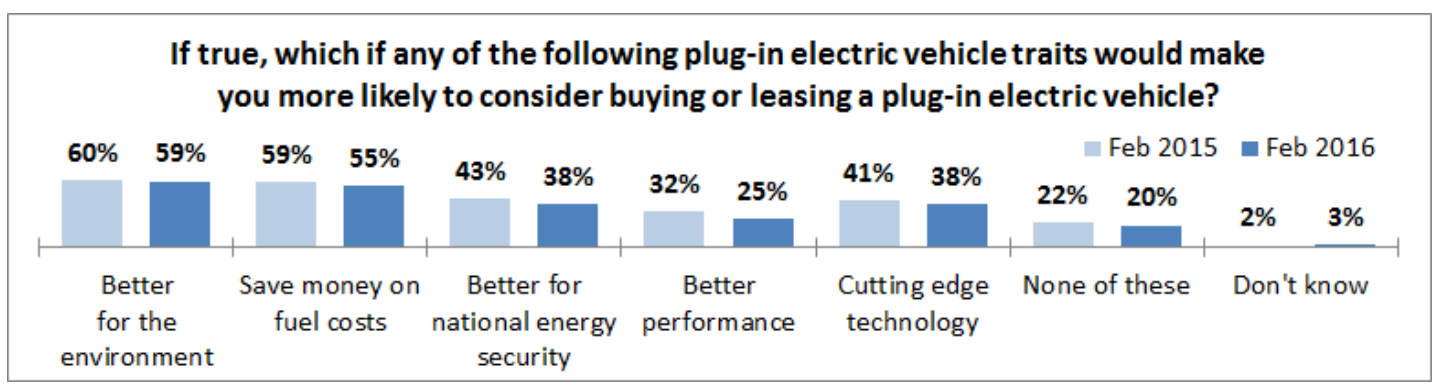

Figure 17. Question 15: PEV traits that could increase purchase consideration

Sources: For 2016: ORC for NREL (2016), Study No. 725068, n=728. For 2015: ORC for NREL (2015), Study No. $724068, \mathrm{n}=787$.

Note: See note about the information provided to respondents before question 8 in Section 2.3. 


\section{Barriers to Plug-in Electric Vehicle Acceptance}

\section{Contents}

3.1 Barriers to Plug-in Electric Vehicle Acceptance Overview .........................................18

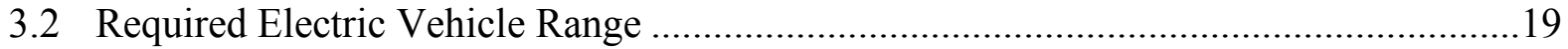

3.3 Perceived Ability to Charge a Plug-in Electric Vehicle .............................................20

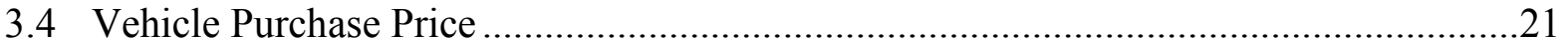

3.5 Willingness to Pay for a Plug-in Electric Vehicle ...................................................22 


\subsection{Barriers to Plug-in Electric Vehicle Acceptance Overview}

Advanced vehicle technologies may have characteristics that require some familiarization by the market before they are considered by potential purchasers. Understanding barriers to broad acceptance can help determine the market for those vehicles and future potential.

The electric distance, or range, AEVs can travel on a single charge is limited by battery size or capacity. Depending on the size of the AEV battery and the type of charging equipment available, the vehicle may require considerable time to recharge. A gasoline vehicle is limited by the distance the vehicle can travel on a single tank of gasoline, but gasoline stations are relatively prevalent, and gasoline vehicles are relatively quick to refuel.

This study asked respondents to provide the vehicle range they would require of an AEV in order for them to consider purchasing one. The results show that a broad set of vehicle ranges would be sufficient for different respondents. The vehicles would need to travel 100 miles on a single charge for $20 \%$ of respondents to consider the vehicles; however, the vehicles would need to travel 400 miles for a majority (55\%) of respondents to consider purchasing the vehicles. Of those respondents providing a range, the median required vehicle range increased from 250 miles in 2015 to 300 miles in 2016.

Recharging opportunity can also influence PEV acceptance. This study found $20 \%$ of respondents were aware of charging stations that they passed regularly, were at their places of work, or were at the stores and places they frequented. This percentage is an increase (within the margin of error) compared to $18 \%$ in 2015 . A large majority (76\%) of respondents were not aware of any charging stations. The percentage who stated they could park their vehicles near electrical outlets at home is down from prior years and in this study was just below half (49\%).

The purchase price of PEVs may deter some purchasers. PEVs are available in a range of prices, but as a new technology they are often more expensive than similar gasoline vehicles. Federal and state tax incentives can play a role in reducing the cost for the purchaser (AFDC 2016). This study found a range of vehicle prices respondents were expecting to pay for their next vehicles. A majority (69\%) stated they expected to pay $\$ 30,000$ or less for their next vehicle, and $43 \%$ expected to pay $\$ 20,000$ or less. Although price is a barrier, current top-selling nonluxury PEV offerings fall within the reported expected price range of $44 \%$ of respondents, if they could all take advantage of the federal tax credit (IRS 2016). Expected purchase prices showed little change from 2015 results.

Respondents showed some willingness to pay increased upfront costs for a PEV that would reduce their fuel costs by one-third. The percentage of respondents who would pay an incremental cost for a PEV decreased within the margin of error from 51\% in 2015 to $49 \%$ in 2016. An additional $22 \%$ would consider a PEV, but would not pay an increased cost. The percentage stating they would not consider a PEV increased from 14\% in 2015 to $18 \%$ in 2016. 


\subsection{Required Electric Vehicle Range}

Respondents provided a wide array of AEV mile ranges that would be necessary for them to consider purchasing AEVs. Respondents in 2016 responded with higher vehicle ranges than in 2015. Of those respondents providing a range, the median provided range was 300 miles in 2016 compared to 250 miles in 2015 . A majority of all respondents (55\%) provided a range of 400 miles or less. Similarly $33 \%$ provided a range of 200 miles or less. A fifth of respondents (20\%) stated a range of 100 miles or less. A smaller percentage of respondents $(9 \%)$ would not consider purchasing AEVs regardless of the vehicle range. To put these ranges in context, the median driving range for model year 2016 gasoline vehicles is 412 miles (EERE 2016).

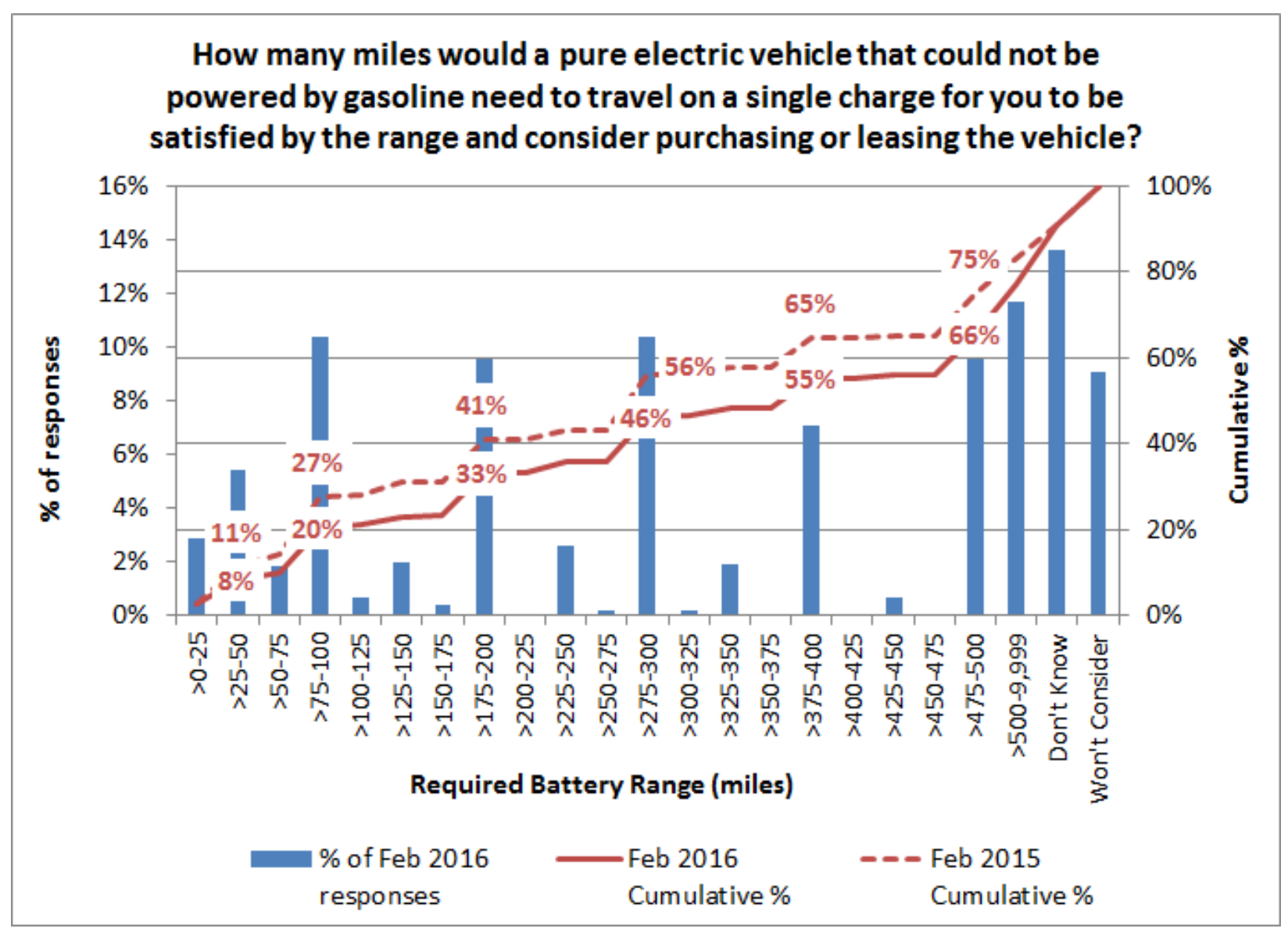

Figure 18. Question 16: Required AEV range for purchase consideration

Sources: For 2016: ORC for NREL (2016), Study No. 725068, n=1,008. For 2015 ORC for NREL (2015), Study No. 724068, $n=1,015$.

Note: Respondents were given the following information before being asked about their exposure to and opinion of PEVs beginning with question 8: "Plug-in electric vehicles can be charged by being plugged into a household-type outlet or specially designed charging equipment. These can be defined as plug-in hybrids or pure electric vehicles. Not included in this definition are hybrids, such as the original Toyota Prius, that cannot be plugged in. The Chevy Volt is an example of a plug-in hybrid electric vehicle that can be powered by either the battery or the gasoline engine. The Tesla Model S or the Nissan Leaf are examples of pure electric vehicles powered only by their batteries." 


\subsection{Perceived Ability to Charge a Plug-in Electric Vehicle}

Respondents reported a low perceived availability of PEV charging stations. Overall, only $20 \%$ of respondents were aware of any charging stations that were on the routes they drove regularly, were at their places of work, or were at the stores and places they frequented. This percentage is up within the margin of error from $18 \%$ in 2015 . Nearly half (49\%) stated they park their primary vehicles near electrical outlets at home. Thus, feasibly, these vehicles could be charged at the respondents' homes. The percentage of respondents who parked near outlets was lower than when respondents were previously asked in April 2006 and February 2015. Section 4 of this report investigates PEV acceptance by different respondent groups including those who are aware of charging stations and those who are able to plug in at home.

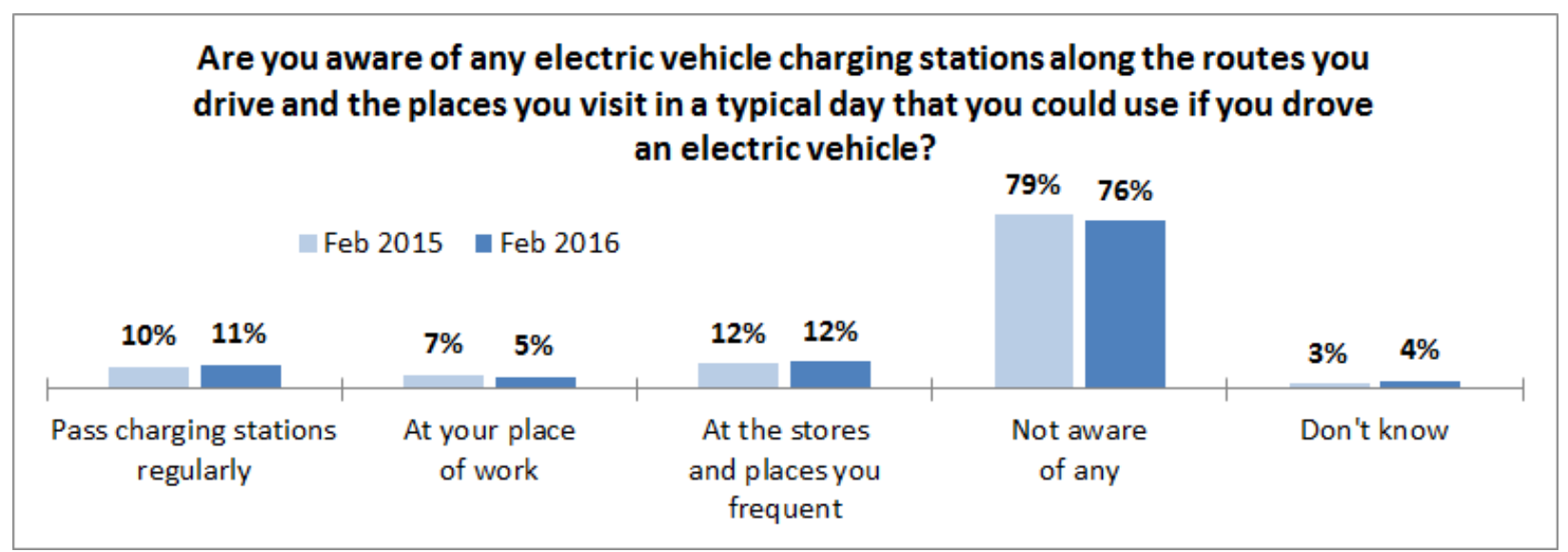

Figure 19. Question 17: Awareness of PEV charging stations

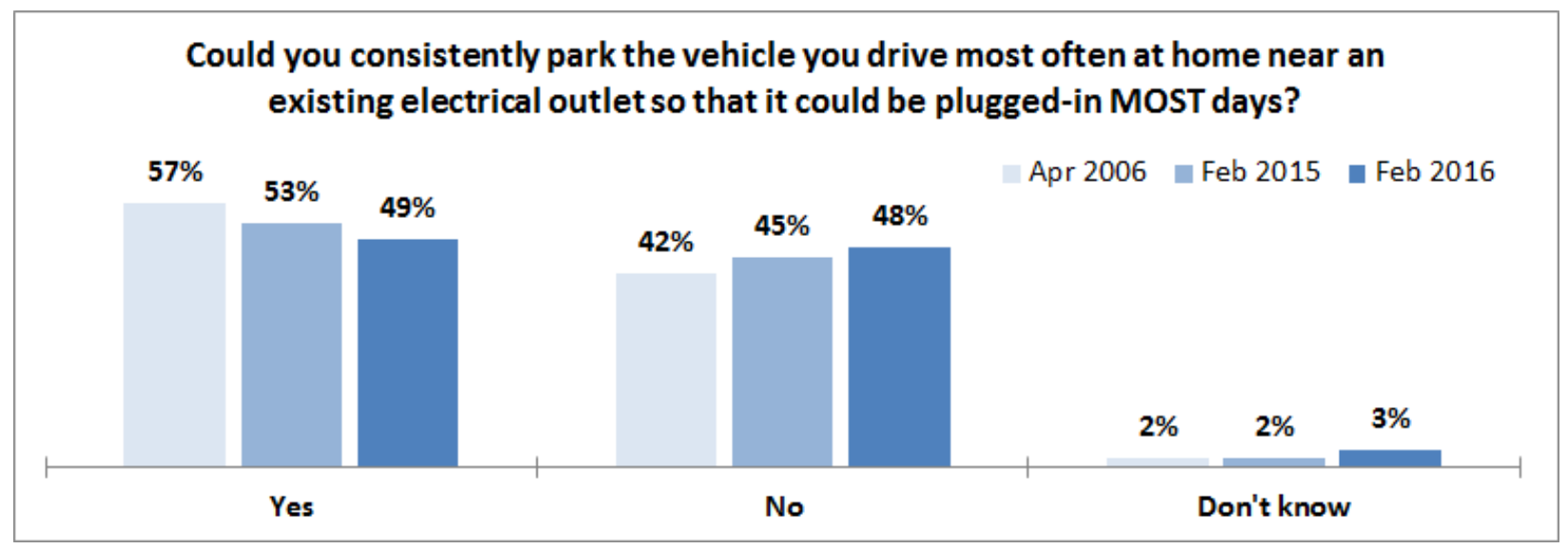

Figure 20. Question 18: Ability to charge a PEV at home

Sources: For 2016: ORC for NREL (2016), Study No. 725068, n=1,008. For 2015: ORC for NREL (2015), Study No. 724068, $n=1,015$. For 2006: ORC for NREL (2006), Study No. $715168, n=480$.

Note: In Section 4 of this report, the $20 \%$ segment of respondents who were aware of any charging stations that were on the routes they drove regularly, were at their places of work, or were at the stores and places they frequented were classified as "aware of PEV charging stations." 


\subsection{Vehicle Purchase Price}

Respondents provided a wide range of expected purchase prices for their next vehicles. A majority (69\%) expected to spend $\$ 30,000$ or less, and $43 \%$ expected to pay $\$ 20,000$ or less. In January 2016, the top-selling PHEV was the Chevrolet Volt and the top-selling nonluxury AEV was the Nissan Leaf (ANL 2016). In March 2016, the Volt retail price was $\$ 33,170$ (Chevrolet 2016) and the Leaf retail price was $\$ 29,010$ (Nissan 2016). If the federal tax credit of $\$ 7,500$ is subtracted from the vehicle prices (IRS 2016), the Leaf cost of $\$ 21,510$ would be in the price range of $44 \%$ of respondents; the Volt cost of $\$ 25,670$ would be in the range of $34 \%$ of respondents. The distribution of expected purchase prices by respondents was consistent with 2015 results.

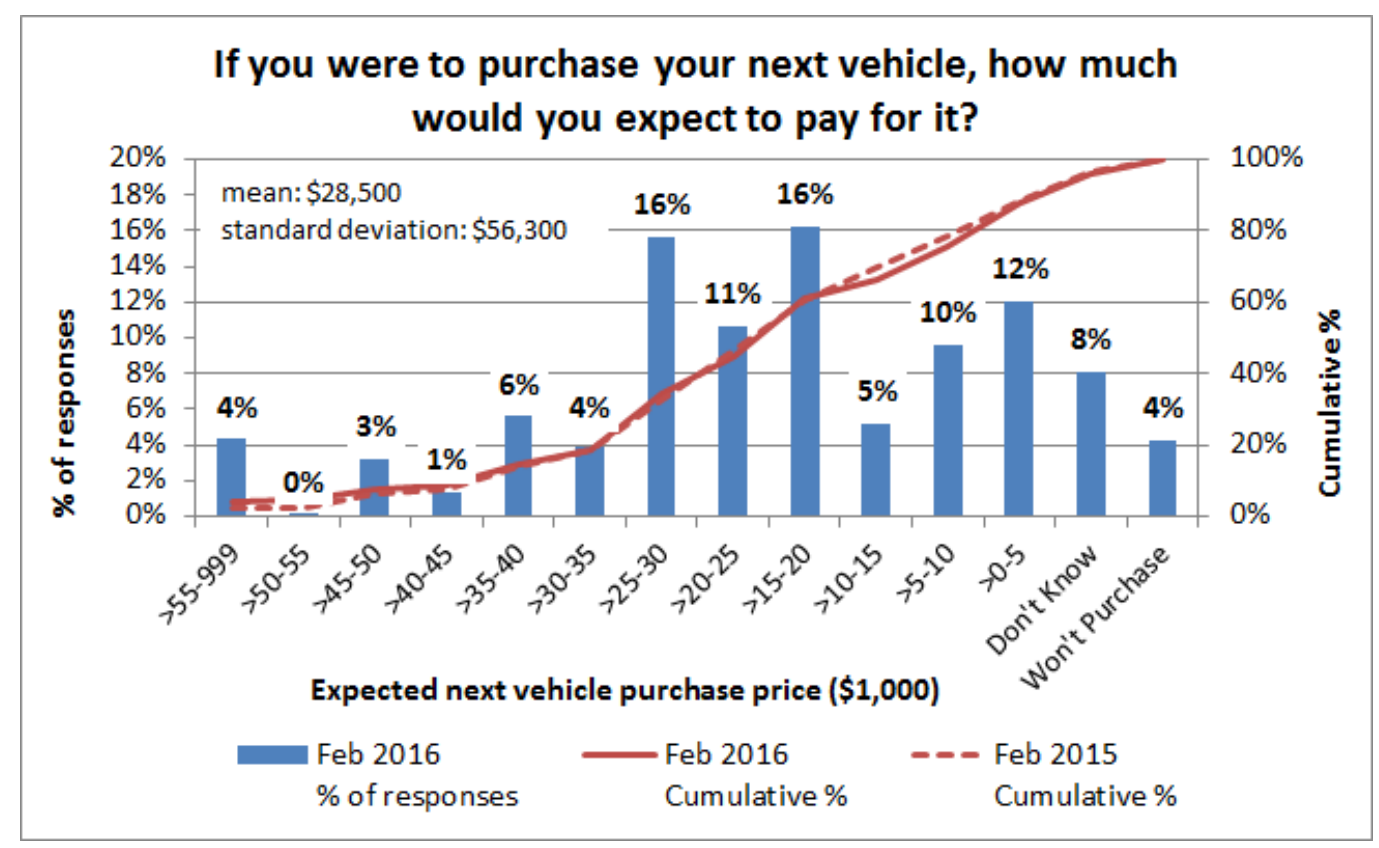

Figure 21. Question 19: Expected next vehicle purchase price

Sources: For 2016: ORC for NREL (2016), Study No. 725068, n=1,008. For 2015: ORC for NREL (2015), Study No. $724068, n=1,015$.

Notes: The results of this question are not intended to show what respondents have paid or will actually pay for their vehicles. The data are reflecting respondent current expectations, which may differ significantly from final purchase decisions.

The federal tax credit begins to phase out after a specific manufacturer sells 200,000 qualifying PEVs (IRS 2016). Chevrolet and Nissan are not expected to reach the cap soon as the Volt and Leaf had each sold roughly 100,000 units as of October 2016 (ANL 2016). 


\subsection{Willingness to Pay for a Plug-in Electric Vehicle}

Respondents showed a diverse willingness to pay ncremental costs for PEVs that would cut their fuel costs by one-third. Roughly half (49\%) stated they would be willing to pay an incremental cost, and an additional $22 \%$ of respondents would not pay an incremental cost, but would consider the hypothetical PEV. Finally, 18\% would not buy PEVs regardless of incremental costs. Respondent willingness to pay an incremental cost for a PEV was similar to 2015 results. There was a small increase (16\% in 2015 compared to 19\% in 2016) in respondents reporting a willingness to pay an incremental cost more than $\$ 5,000$. There was also an increase in respondents who would not buy a PEV even without an incremental cost (14\% in 2015 and $18 \%$ in 2016).

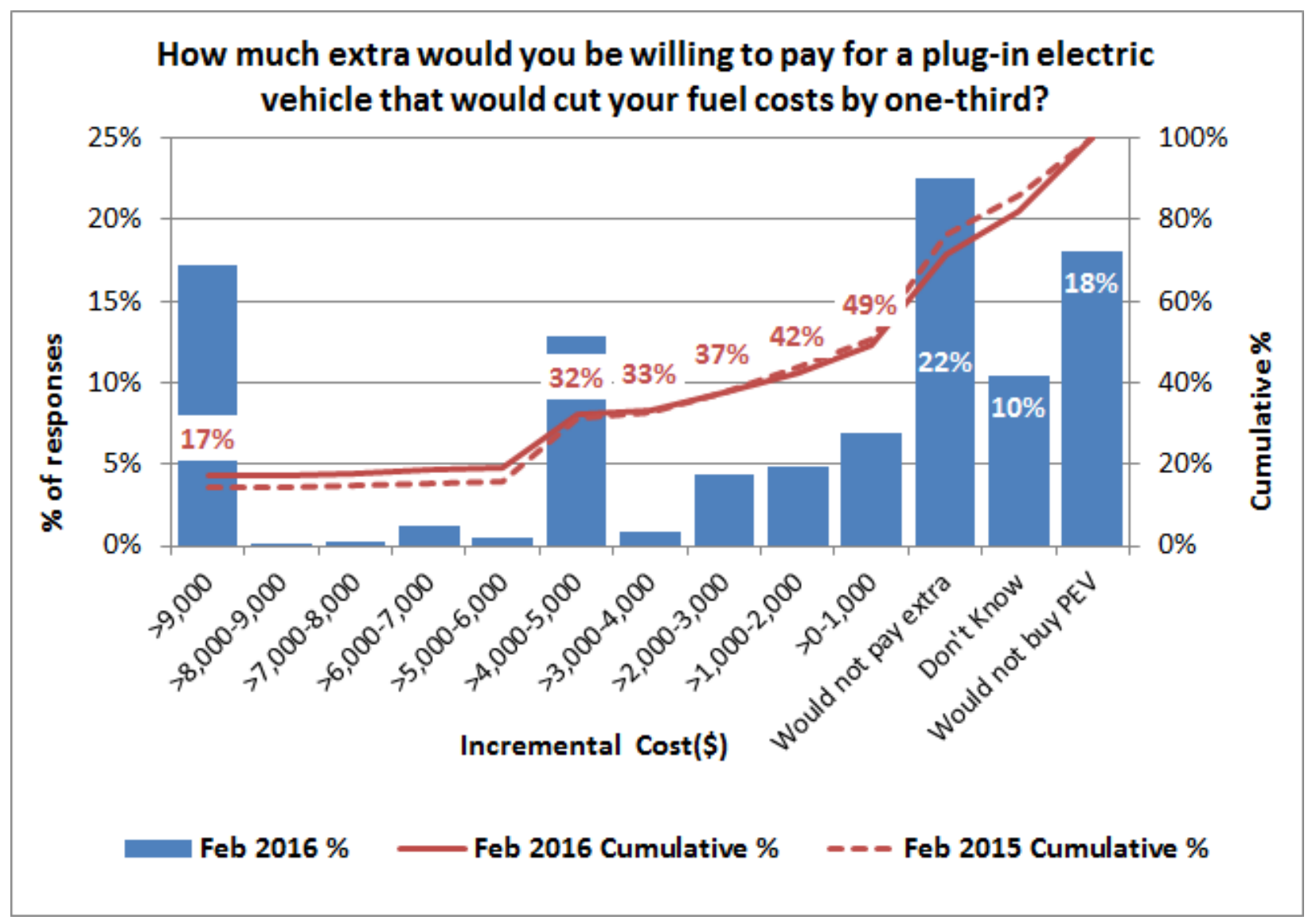

Figure 22. Question 20: Willingness to pay for a PEV

Sources: For 2016: ORC for NREL (2016), Study No. 725068, n=1,008. For 2015: ORC for NREL (2015), Study No. $724068, n=1,015$. 


\section{Plug-in Electric Vehicle Acceptance}

\section{Contents}

4.1 Plug-in Electric Vehicle Acceptance Overview .....................................................24

4.2 Perception of Plug-in Hybrid Electric vs. Conventional Vehicles ...............................27

4.3 Perception of All-Electric vs. Conventional Vehicles..................................................28

4.4 Willingness to Consider Plug-in Hybrid Electric Vehicles by Segment.......................29

4.5 Willingness to Consider All-Electric Vehicles by Segment.......................................30

4.6 Demographics of Plug-in Electric Vehicle Perceptions ..............................................31

4.7 Demographics of Willingness to Consider Plug-in Electric Vehicles...........................32 


\subsection{Plug-in Electric Vehicle Acceptance Overview}

A broad set of factors affect consumers' willingness to purchase vehicles. Even when considering established technologies, consumers' interest and purchase behavior varies to meet their transportation needs. For a new vehicle technology to succeed, consumers will need to become aware of the technology and accept how the new technology can meet their needs.

Questions 9 and 11 (see Section 2.4) identified segments of respondents who believe that PEVs are just as good as or better than traditional gasoline vehicles. Similarly, questions 10 and 12 (see Section 2.5) identified segments of respondents who either expect to purchase PEVs or expect to consider purchasing PEVs. These response sets were used as measures of PEV acceptance.

This section identifies additional segments and compares their levels of PEV acceptance to each other and the overall respondent group. The sample sizes for these investigations, as noted in the coming pages for each graphic, are smaller than the study overall, but the comparisons highlight where stronger acceptance of PEVs originated in this study. Select segments of respondents were defined as follows:

- New or used vehicle purchasers (see Section 1.5)

- Vehicle purchasers who bought or plan to buy within one year (see Section 1.4)

- Single- or multivehicle households (see Section 1.2)

- Respondents able to name one of the top 10 best-selling PEVs (see Section 2.2)

- Respondents who have seen PEVs in parking lots (see Section 2.3)

- Respondents who have seen PEV advertisements (see Section 2.3)

- Respondents who have seen PEVs in social media (see Section 2.3)

- Respondents who are aware of PEV tax incentives (see Section 2.3)

- Respondents aware of PEV charging stations (see Section 3.3)

- Respondents able to plug in at home (see Section 3.3).

Additionally, respondent demographics captured by the ORC study allowed investigation of variations in PEV acceptance by respondent age, household income, and education levels.

Overall, respondents were more likely to view PHEVs positively than AEVs. This relationship held true across all respondent sub-groupings investigated. The only exception was singlevehicle households, which were slightly more likely to believe AEVs, in comparison to PHEVs, were as good as or better than traditional gasoline vehicles ( $47 \%$ to $46 \%$, respectively). This difference was within the margin of error.

In comparison to all the respondent segments investigated, those who were aware of existing PEV charging stations in their vicinity were most likely to report that PEVs were as good as or better than traditional gasoline vehicles and were most likely to consider purchasing a PEV. Respondents who were aware of PEV charging stations were twice as likely to report a willingness to consider purchasing a PEV. Similarly, respondents able to plug in at home were more likely to agree with the positive PEV sentiments. 
More broadly, in addition to charging station awareness, respondents with more exposure and awareness of PEVs reported the positive PEV sentiments. Respondents who have seen PEVs in parking lots, PEV advertisements, or PEVs in social media; were able to name a specific PEV make and model; or were aware of PEV tax incentives consistently reported higher levels of PEV acceptance and willingness to consider purchasing PEVs.

PEV acceptance did not vary greatly between single-vehicle and multivehicle households. Single-vehicle households more often than multivehicle households reported that AEVs are as good as or better than traditional gasoline vehicles - in 2015 multivehicle households more often agreed with the positive view of AEVs. Multivehicle households were slightly more likely than single-vehicle households to report an expectation to consider purchasing a PHEV (25\% and $22 \%$, respectively). Single-vehicle households were slightly more likely to expect to consider an AEV than multivehicle households (21\% and 19\%, respectively), although the difference was within the margin of error.

New and used vehicle purchasers showed little variation in PEV sentiments. New vehicle purchasers were more likely than used vehicle purchasers to consider PHEVs to be just as good as or better than traditional gasoline vehicles.

Those respondents most recently active in the market, which was determined by their having purchased a vehicle in the last year or their expectation to purchase in the next year, did not show a large difference in their PEV sentiments from the overall respondent group.

Compared to 2015, fewer respondents viewed PEVs as just as good as or better than traditional gasoline vehicles. Only the percentage of respondents having the positive view of AEVs increased significantly from 2015.

The percentages of respondents overall who would be willing to consider purchasing PEVs declined only slightly from 2015 . Used vehicle purchasers were more likely to consider PEVs in 2016, while new vehicle purchasers were less likely to do so than in 2015. Those respondents aware of PEV charging stations, while already much more likely to consider PEVs than the overall respondent group, were even more likely in 2016 than in 2015 to consider purchasing PEVs.

Of the demographic groups investigated, respondents aged 35 or younger were most likely to state that PEVs were as good as or better than traditional gasoline vehicles and were most likely to consider purchasing a PEV. Respondents over 55 were least likely to have the positive PEV sentiments.

When investigating respondent income levels, those respondents with an annual household income less than $\$ 50,000$ were most likely to state AEVs were as good as or better than traditional gasoline vehicles. However, the income groups above $\$ 50,000$ were more likely to say PHEVs were as good as or better than traditional gasoline vehicles. When asked about their willingness to consider purchasing a PEV, income groups showed more distinct variations.

Respondents with a household income under $\$ 50,000$ were less likely than the full respondent set to state a willingness to consider purchasing a PEV, while respondents with household incomes over $\$ 50,000$ were more likely to consider purchasing a PEV. 
Finally, respondents with some college education or college degrees were more likely to view PHEVs to be as good as or better than traditional gasoline vehicles. Respondents with some college, but without a college degree were most likely to view AEVs to be as good as or better than traditional gasoline vehicles. Respondents with some college or college degrees were more likely to report a willingness to consider purchasing PEVs. 


\subsection{Perception of Plug-in Hybrid Electric vs. Conventional Vehicles}

Overall, $46 \%$ of respondents stated that PHEVs were just as good as or better than gasoline vehicles. A sampling of respondent segments is shown in Figure 23. Acceptance of PHEVs based on this measure was down from $52 \%$ in the 2015 study. Respondents who reported being aware of charging stations had the highest percentage $(56 \%)$ reporting a positive view. Similarly, respondents able to plug-in at home were more likely to report the positive view. Respondents reporting an awareness of PEVs (those who could name one of the top bestselling PEVs, those who had seen PEVs in parking lots, seen PEV ads, seen PEVs in social media, or were aware of PEV tax incentives) were more likely to report a positive view.

PHEV acceptance was higher among new vehicle purchasers than used vehicle purchasers. Little difference in PHEV acceptance was reported between single and multivehicle households.

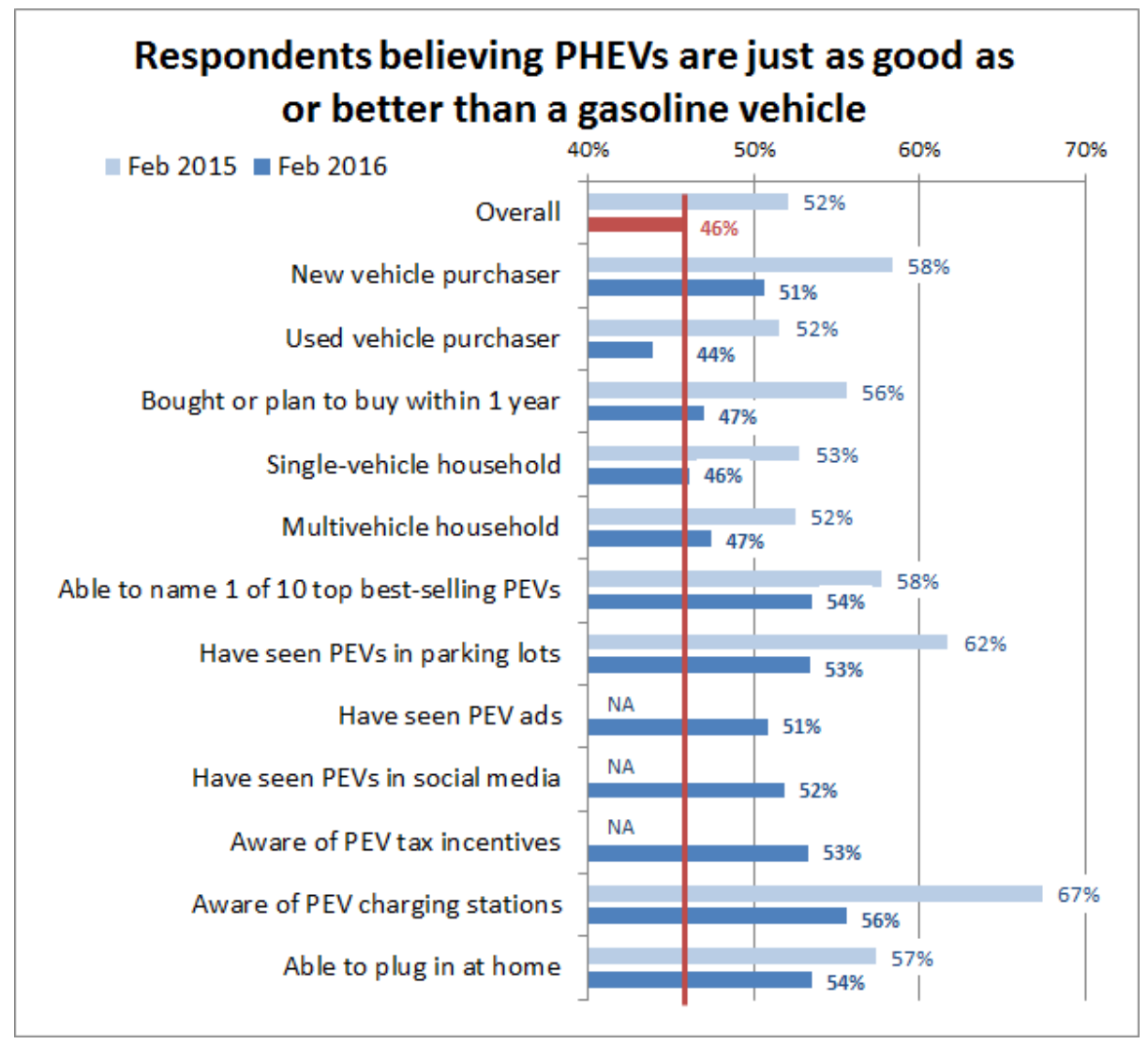

Figure 23. Segments of PHEV acceptance

Sources: For 2015 (Singer 2016). For 2016: ORC for NREL (2016), Study No. 725068, see note for sample sizes.

Note: Respondents were not asked about PEV advertisements, PEVs in social media, or PEV tax incentives in 2015. The overall sample size was $n=1,008$. Sample sizes for the respondents who also fit in the additional segments were generally small and were as follows: new vehicle purchasers $(n=444)$, used vehicle purchasers $(n=338)$, bought or planned to buy within one year $(n=390)$, single-vehicle households $(n=307)$, multivehicle households $(n=583)$, able to name one of the 10 top-selling PEVs $(n=414)$, have seen PEVs in parking lots $(n=434)$, have seen PEV ads $(n=576)$, have seen PEVs in social media $(n=543)$, are aware of PEV tax incentives $(n=332)$, are aware of PEV charging stations $(n=197)$, and able to plug in at home $(n=495)$. 


\subsection{Perception of All-Electric vs. Conventional Vehicles}

Overall, $41 \%$ of respondents stated that AEVs were just as good as or better than gasoline vehicles. A sampling of respondent segments is shown in Figure 24. Acceptance of AEVs based on this measure was down from $45 \%$ in the 2015 study. Respondents who reported being aware of charging stations had the highest percentage $(55 \%)$ reporting a positive view. Respondents able to plug-in at home were also more likely to report the positive view. Respondents reporting an awareness of PEVs (those who could name one of the top bestselling PEVs, those who had seen PEVs in parking lots, seen PEV ads, seen PEVs in social media, or were aware of PEV tax incentives) were more likely to report a positive view. Little difference in AEV acceptance was reported between new and used vehicle purchasers. Singlevehicle households reported a higher acceptance of AEVs than multivehicle households, after the opposite was reported in 2015.

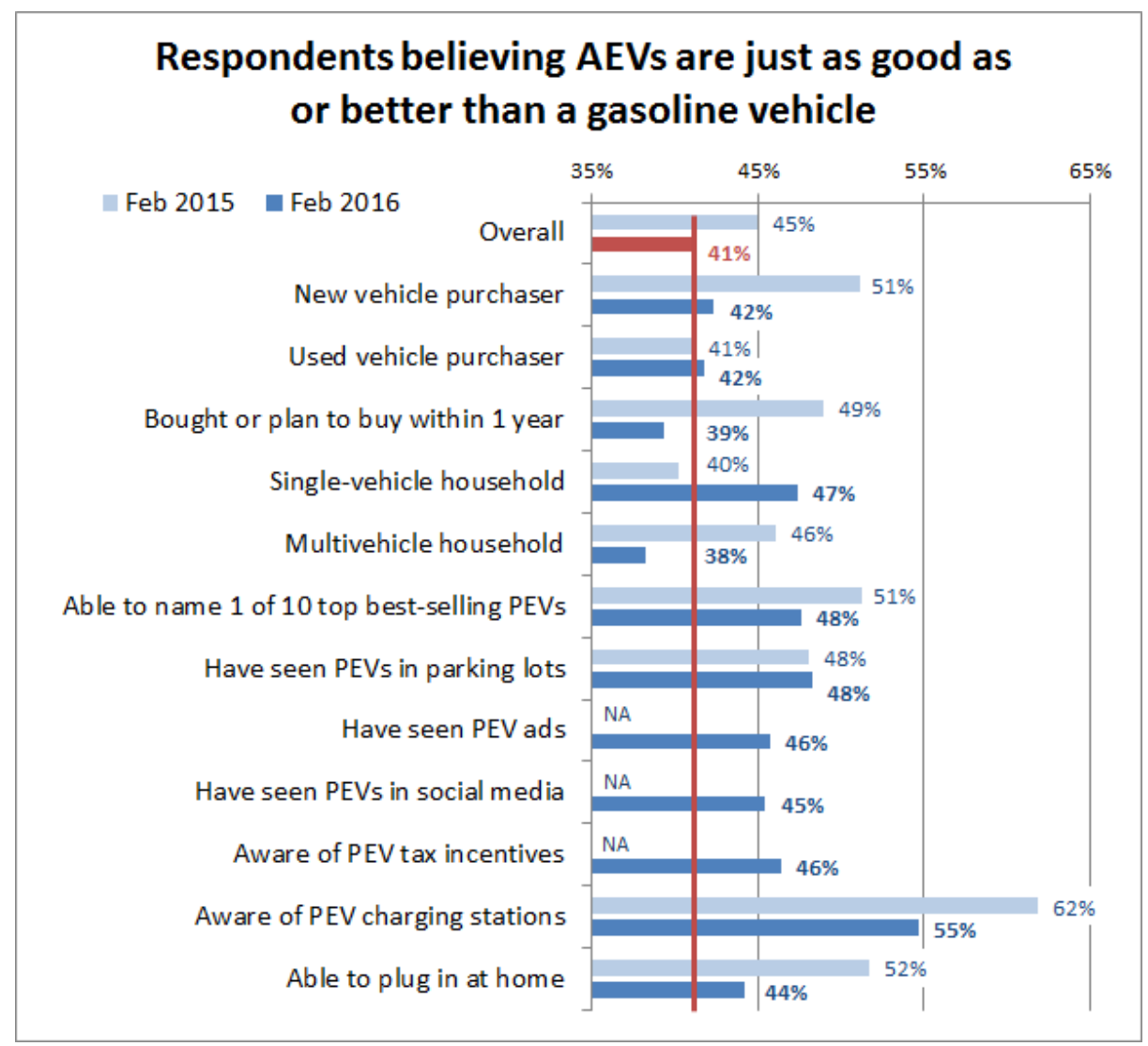

Figure 24. Segments of AEV acceptance

Sources: For 2015 (Singer 2016). For 2016: ORC for NREL (2016), Study No. 725068, see note for sample sizes.

Note: Respondents were not asked about PEV advertisements, PEVs in social media, or PEV tax incentives in 2015. The overall sample size was $n=1,008$. Sample sizes for the respondents who also fit in the additional segments were generally small and were as follows: new vehicle purchasers $(n=444)$, used vehicle purchasers $(n=338)$, bought or planned to buy within one year $(n=390)$, single-vehicle households $(n=307)$, multivehicle households $(n=583)$, able to name one of the 10 top-selling PEVs $(n=414)$, have seen PEVs in parking lots $(n=434)$, have seen PEV ads ( $n=576)$, have seen PEVs in social media $(n=543)$, are aware of PEV tax incentives $(n=332)$, are aware of PEV charging stations $(n=197)$, and able to plug in at home $(n=495)$. 


\subsection{Willingness to Consider Plug-in Hybrid Electric Vehicles by Segment}

Overall, $23 \%$ of respondents stated they would purchase or consider PHEVs for their next vehicle purchases or leases. A sampling of respondent segments is shown in Figure 25. Willingness to consider PHEVs based on this measure was down within the margin of error from $24 \%$ in the 2015 study. Respondents who reported being aware of charging stations had the highest percentage (46\%) expecting to consider a PHEV. Similarly, respondents able to plug-in at home were more likely to report the positive view. Respondents reporting an awareness of PEVs (those who could name one of the top best-selling PEVs, those who had seen PEVs in parking lots, seen PEV ads, seen PEVs in social media, or were aware of PEV tax incentives) were more likely to consider a PHEV. Willingness to consider a PHEV was slightly higher among new vehicle purchasers than used vehicle purchasers, although used purchaser interest increased from 2015. Multivehicle households were slightly more likely to consider purchasing PHEVs than single-vehicle households.

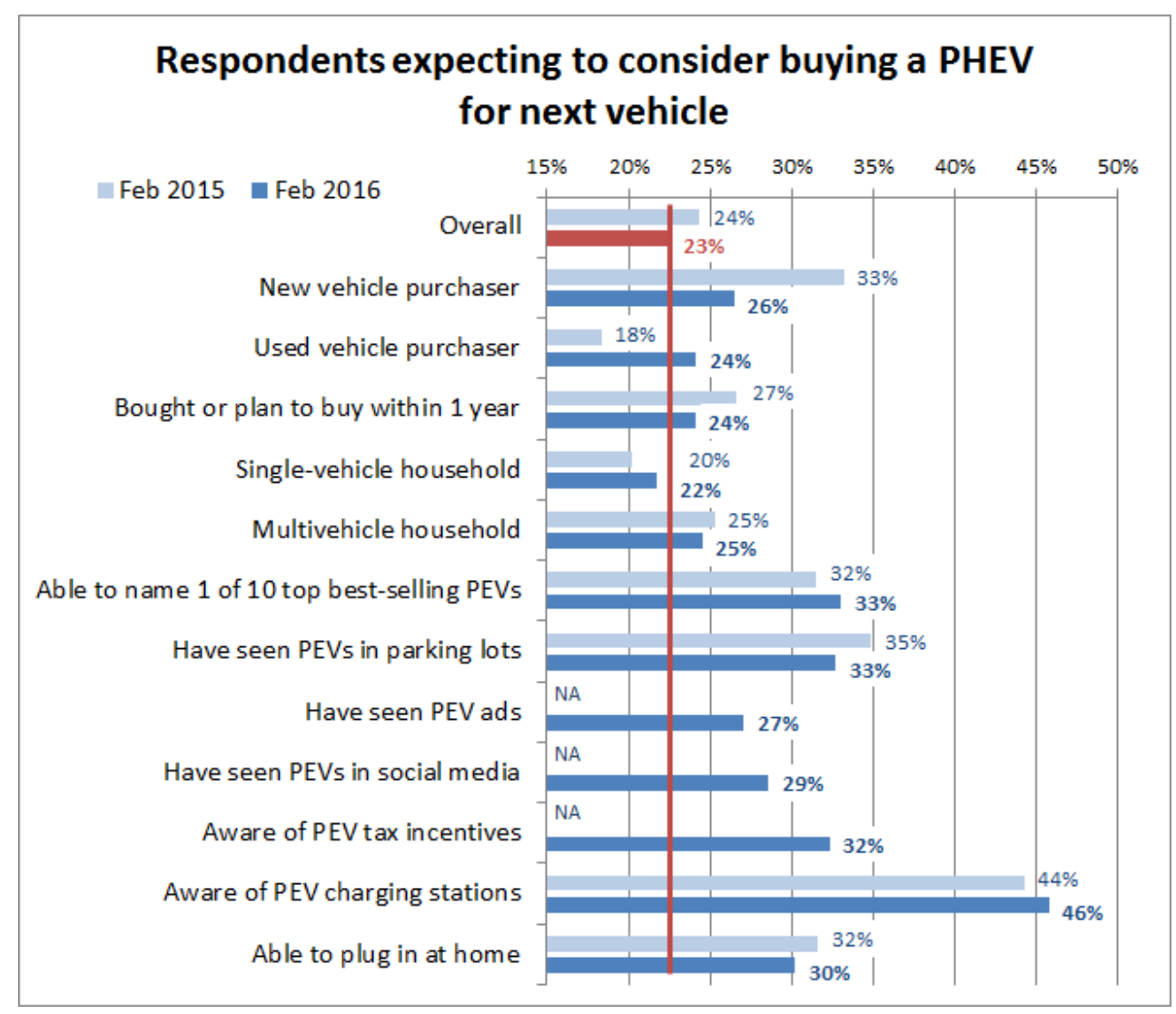

Figure 25. Willingness to consider PHEVs by segment

Sources: For 2015 (Singer 2016). For 2016: ORC for NREL (2016), Study No. 725068, see note for sample sizes.

Note: Respondents were not asked about PEV advertisements, PEVs in social media, or PEV tax incentives in 2015. The overall sample size was $n=1,008$. Sample sizes for the respondents who also fit in the additional segments were generally small and were as follows: new vehicle purchasers $(n=444)$, used vehicle purchasers $(n=338)$, bought or planned to buy within one year $(n=390)$, single-vehicle households $(n=307)$, multivehicle households $(n=583)$, able to name one of the 10 top-selling PEVs $(n=414)$, have seen PEVs in parking lots $(n=434)$, have seen PEV ads ( $n=576)$, have seen PEVs in social media $(n=543)$, are aware of PEV tax incentives $(n=332)$, are aware of PEV charging stations $(n=197)$, and able to plug in at home $(n=495)$. 


\subsection{Willingness to Consider All-Electric Vehicles by Segment}

Overall, 19\% of respondents stated they would purchase or consider AEVs for their next vehicle purchases or leases. A sampling of respondent segments is shown in Figure 26. Willingness to consider AEVs based on this measure was down within the margin of error from $20 \%$ in the 2015 study. Respondents who reported being aware of charging stations had the highest percentage (40\%) expecting to consider an AEV. Similarly, respondents able to plug-in at home were more likely to report the positive view. Respondents reporting an awareness of PEVs (those who could name one of the top best-selling PEVs, those who had seen PEVs in parking lots, seen PEV ads, seen PEVs in social media, or were aware of PEV tax incentives) were more likely to consider an AEV. Willingness to consider an AEV was similar between new vehicle purchasers and used vehicle purchasers, but used purchaser interest increased from 2015. Multivehicle households were slightly less likely to consider purchasing AEVs than single-vehicle households.

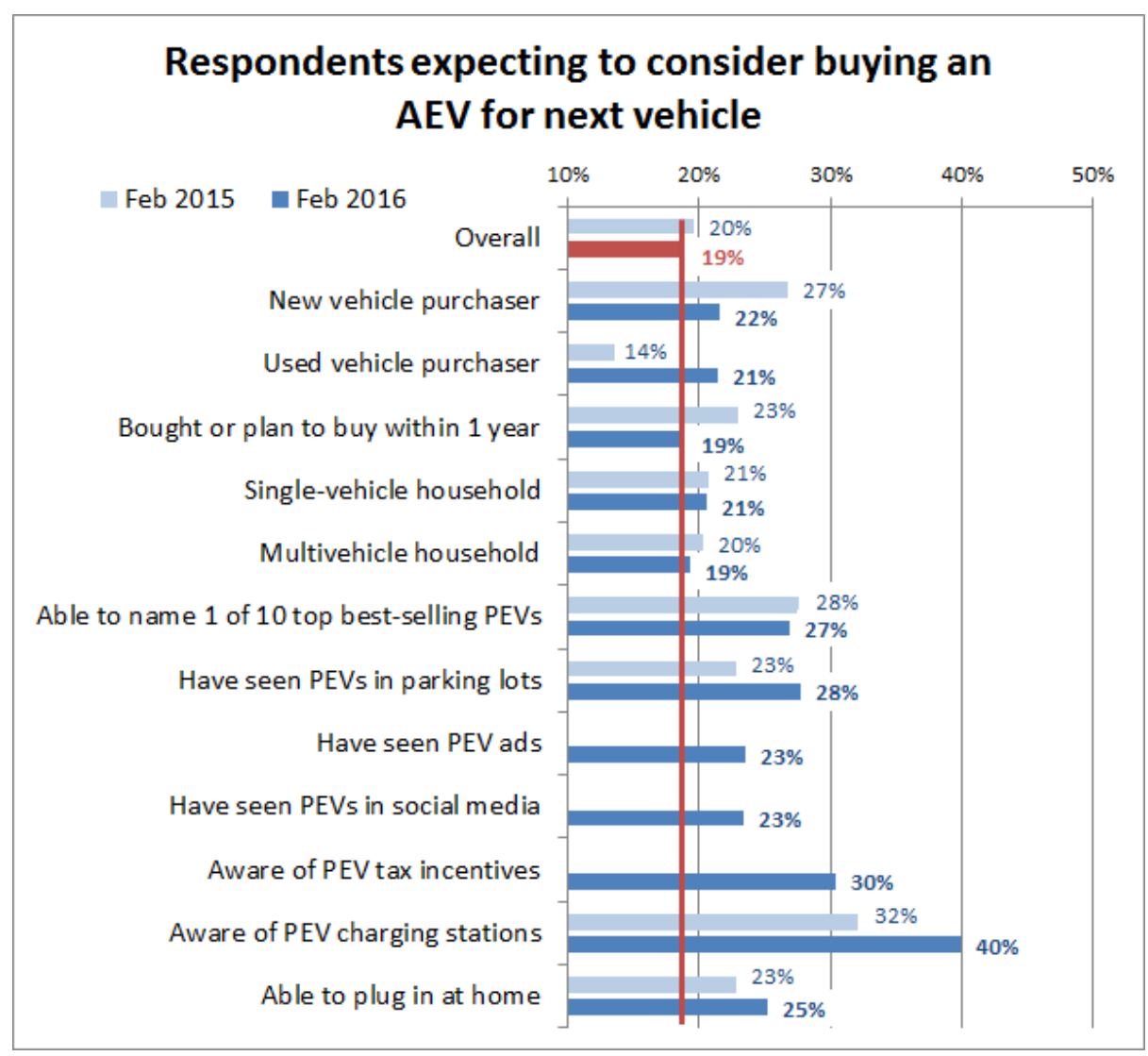

Figure 26. Willingness to consider AEVs by segment

Sources: For 2015 (Singer 2016). For 2016: ORC for NREL (2016), Study No. 725068, see note for sample sizes.

Note: Respondents were not asked about PEV advertisements, PEVs in social media, or PEV tax incentives in 2015. The overall sample size was $n=1,008$. Sample sizes for the respondents who also fit in the additional segments were generally small and were as follows: new vehicle purchasers $(n=444)$, used vehicle purchasers $(n=338)$, bought or planned to buy within one year $(n=390)$, single-vehicle households $(n=307)$, multivehicle households $(n=583)$, able to name one of the 10 top-selling PEVs $(n=414)$, have seen PEVs in parking lots $(n=434)$, have seen PEV ads $(n=576)$, have seen PEVs in social media $(n=543)$, are aware of PEV tax incentives $(n=332)$, are aware of PEV charging stations $(n=197)$, and able to plug in at home $(n=495)$. 


\subsection{Demographics of Plug-in Electric Vehicle Perceptions}

PEV acceptance varied by respondent demographics captured in the study. A sampling of respondent segments is shown in Figure 27. Respondents age 35 or younger reported the highest levels of PEV acceptance. AEV acceptance was highest across income levels among respondent households making less than $\$ 50,000$ a year in comparison to other income brackets. PHEV acceptance was highest across income levels among those households earning between $\$ 50,000$ and $\$ 100,000$. PHEV acceptance was highest among respondents with college degrees in comparison to other levels of education. Across education levels AEV acceptance was highest among those respondents with some college education, but without a bachelor's degree.

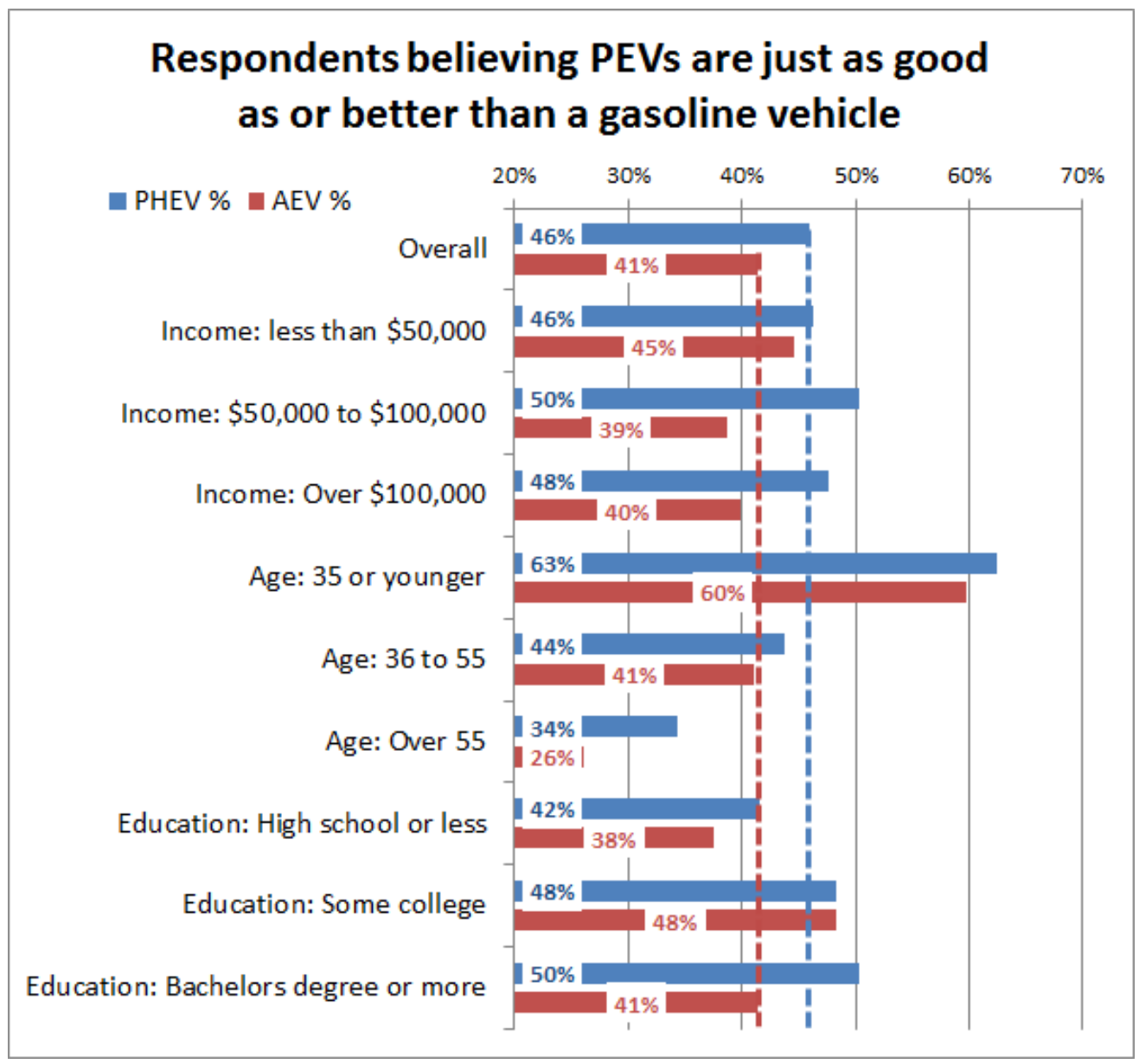

Figure 27. Demographics of PEV acceptance

Source: ORC for NREL (2016), Study No. 725068, see note for sample sizes.

Note: The overall sample size was $n=1,008$. Sample sizes for the respondents of the demographic groups were smaller and were as follows: income less than $\$ 50,000(n=489)$, income $\$ 50,000$ to $\$ 100,000(n=213)$, income over $\$ 100,000$ ( $n=154), 35$ years and younger $(n=307), 36$ to 55 years of age $(n=339)$, over 55 years $(n=333)$, high school diploma or less $(n=398)$, some college $(n=269)$, and bachelor's degree or higher $(n=309)$. 


\subsection{Demographics of Willingness to Consider Plug-in Electric Vehicles}

Respondents from different demographic groups reported varied levels of willingness to consider purchasing PEVs. A sampling of respondent segments is shown in Figure 28. Respondents age 35 or younger were most likely to consider purchasing PEVs. Interest declined as age increased. Willingness to consider PEVs was higher for the two higher income segments, while those making less than $\$ 50,000$ were less likely to consider PEVs. Respondents with a high school education or less were less likely to consider PEVs. The two respondent segments who reported having at least some college education reported a similar increased willingness to consider PEVs.

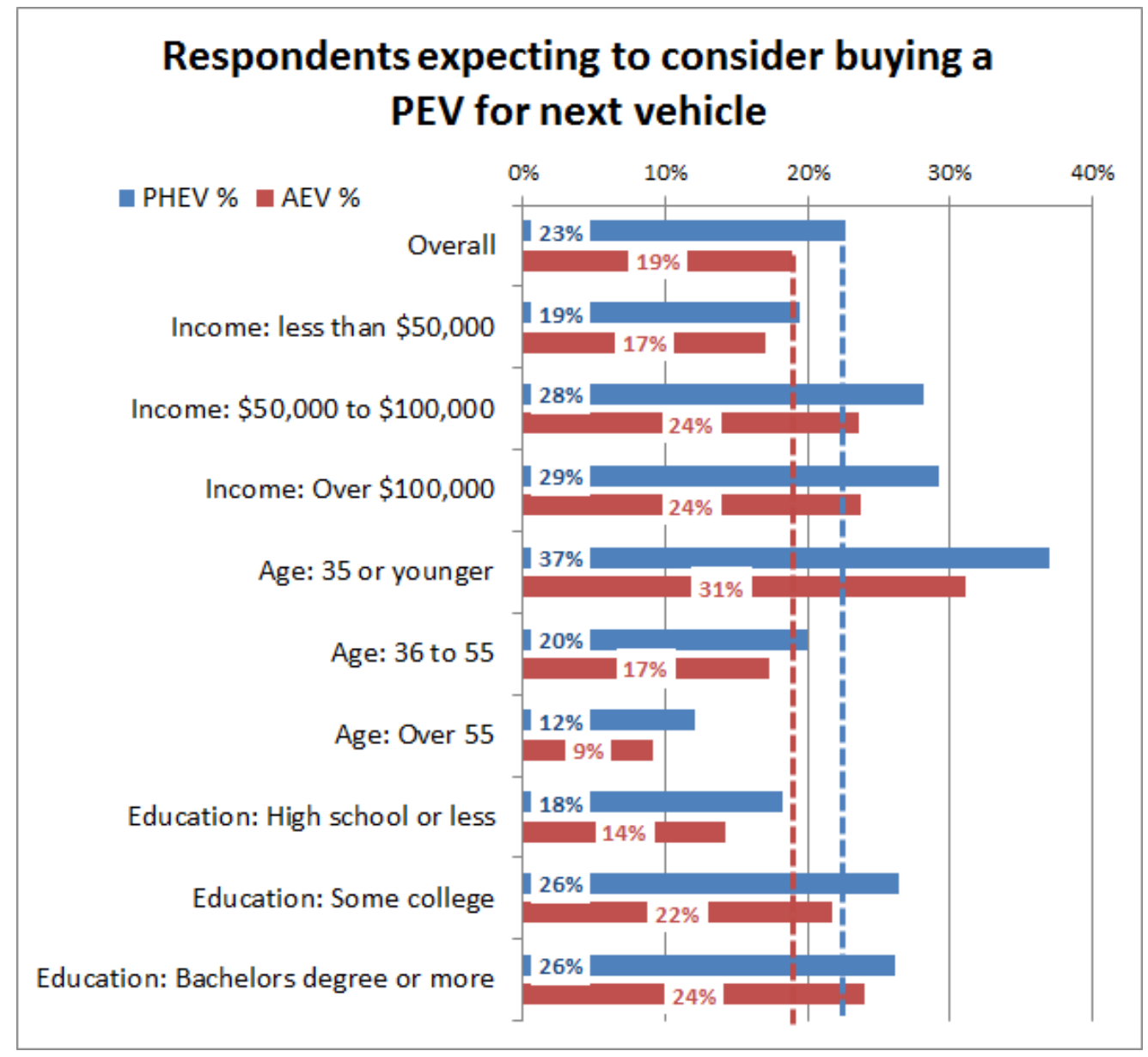

Figure 28. Demographics of willingness to consider PEVs

Source: ORC for NREL (2016), Study No. 725068, see note for sample sizes.

Note: The overall sample size was $n=1,008$. Sample sizes for the respondents of the demographic groups were smaller and were as follows: income less than $\$ 50,000(n=489)$, income $\$ 50,000$ to $\$ 100,000$ ( $n=213)$, income over $\$ 100,000(n=154), 35$ years and younger $(n=307), 36$ to 55 years of age $(n=339)$, over 55 years $(n=333)$, high school diploma or less $(n=398)$, some college $(n=269)$, and bachelor's degree or higher $(n=309)$. 


\section{References}

Alternative Fuels Data Center (AFDC). 2016. "Federal and State Laws and Incentives." Washington, DC: Department of Energy. Accessed November 14, 2016: http://www.afdc.energy.gov/laws.

Argonne National Laboratory (ANL). 2016. "Light Duty Electric Drive Vehicles Monthly Sales Updates.” Lemont, IL: ANL. Accessed October 31, 2016: http://www.anl.gov/energysystems/project/light-duty-electric-drive-vehicles-monthly-sales-updates.

Chevrolet. 2016. “2016 Volt.” Detroit, MI: Chevrolet. Accessed March 8, 2016: http://www.chevrolet.com/volt-electric-car.html.

Energy Information Administration (EIA). 2016. "U.S. All Grades All Formulations Retail Gasoline Prices." Washington, DC: EIA. Accessed October 27, 2016:

http://tonto.eia.gov/dnav/pet/hist/LeafHandler.ashx?n=PET\&s=EMM_EPM0_PTE_NUS_DPG\& $\underline{\mathrm{f}=\mathrm{M}}$.

Internal Revenue Service (IRS). 2016. "Plug-In Electric Drive Vehicle Credit (IRC 30D)." Washington, DC: IRS. Accessed October 11, 2016: https://www.irs.gov/businesses/plug-inelectric-vehicle-credit-irc-30-and-irc-30d.

Keane, M.P., and N. Wasi. 2013. The Structure of Consumer Taste Heterogeneity in Revealed vs. Stated Preference Data. Oxford, U.K.: University of Oxford. Accessed August 2015: www.nuffield.ox.ac.uk/economics/papers/2013/SP_RP_data\%20-\%20Final.pdf.

National Independent Automobile Dealers Association (NIADA). 2015. 2015 Used Car Market Report. Atlanta, GA: Manheim. Accessed November 12, 2015:

http://www.niada.com/uploads/dynamic areas/tRRlH6fX2WoqiCcaonlq/33/2015ManheimUsed CarMarketReport.pdf.

Nissan. 2016. “2016 Nissan Leaf.” Yokohama, Japan: Nissan. Accessed March 8, 2016: www.nissanusa.com/electric-cars/leaf.

Office of Energy Efficiency and Renewable Energy (EERE). 2016. "Fact \#939: August 22, 2016 All-electric Vehicle Ranges Can Exceed Those of Some Gasoline Vehicles." Washington, DC: Department of Energy. Accessed November 14, 2016: http://energy.gov/eere/vehicles/fact-939august-22-2016-all-electric-vehicle-ranges-can-exceed-those-some-gasoline.

Rogers, E.M. 2010. Diffusion of Innovations. 4th Edition. New York, NY: Simon and Schuster. Accessed July 2015:

https://books.google.com/books?id=v1ii4QsB7jIC\&printsec $=$ frontcover\&dq=Theory + of + Diffusi on + of + Innovation + Rogers\&hl=en\&sa $=$ X\&ved=0CCsQ6AEwAWoVChMIlfqX9aCfyAIVihoeC h3bow Q\#v=onepage\&q\&f=false.

Singer, M. 2016. Consumer Views on Plug-in Electric Vehicles - National Benchmark Report. NREL/TP-5400-65279. Golden, CO: National Renewable Energy Laboratory. Accessed August 2, 2016: http://www.nrel.gov/docs/fy16osti/65279.pdf. 